\title{
On the Emergence of the Atlantic Multidecadal SST Signal: A Key Role of the Mixed Layer Depth Variability Driven by North Atlantic Oscillation
}

\author{
Ayako Yamamoto, Hiroaki Tatebe, and Masami Nonaka \\ Japan Agency for Marine-Earth Science and Technology, Yokohama, Japan
}

(Manuscript received 16 April 2019, in final form 8 January 2020)

\begin{abstract}
Despite its wide-ranging potential impacts, the exact cause of the Atlantic multidecadal oscillation/ variability (AMO/AMV) is far from settled. While the emergence of the AMO sea surface temperature (SST) pattern has been conventionally attributed to the ocean heat transport, a recent study showed that the atmospheric stochastic forcing is sufficient. In this study, we resolve this conundrum by partitioning the multidecadal SST tendency into a part caused by surface heat fluxes and another by ocean dynamics, using a preindustrial control simulation of a state-of-the-art coupled climate model. In the model, horizontal ocean heat advection primarily acts to warm the subpolar SST as in previous studies; however, when the vertical component is also considered, the ocean dynamics overall acts to cool the region. Alternatively, the heat flux term is primarily responsible for the subpolar North Atlantic SST warming, although the associated surface heat flux anomalies are upward as observed. Further decomposition of the heat flux term reveals that it is the mixed layer depth (MLD) deepening that makes the ocean less susceptible for cooling, thus leading to relative warming by increasing the ocean heat capacity. This role of the MLD variability in the AMO signature had not been addressed in previous studies. The MLD variability is primarily induced by the anomalous salinity transport by the Gulf Stream modulated by the multidecadal North Atlantic Oscillation, with turbulent fluxes playing a secondary role. Thus, depending on how we interpret the MLD variability, our results support the two previously suggested frameworks, yet slightly modifying the previous notions.
\end{abstract}

\section{Introduction}

Oceanic modes of variability are instrumental in Earth's climate system due to its large thermal inertia, modulating the low-frequency climate components (Bjerknes 1964; Gulev et al. 2013; Yamamoto et al. 2015). Of particular importance among such low-frequency modes of oceanic variability is Atlantic multidecadal oscillation/variability (AMO/AMV). AMO is a multidecadal fluctuation of the sea surface temperature (SST) exhibiting a horseshoe-like spatial pattern over the North Atlantic basin, with a period of about 55-90 years in the observational record (Schlesinger and Ramankutty 1994; Kushnir 1994; Ting et al. 2009). AMO has garnered much attention due to its wide-ranging potential impacts over the Northern Hemisphere, including modulation of European climate (e.g., Sutton and Dong 2012; O'Reilly et al. 2017), Sahel drought (Rowell et al. 1995), summertime Asian monsoon (Lu et al. 2006), Atlantic hurricane (Goldenberg

Corresponding author: Ayako Yamamoto, ayako.yamamoto@ jamstec.go.jp et al. 2001), sea ice variability (e.g., Peings et al. 2016), and large-scale atmospheric circulation such as the Atlantic jet and storm track (Woollings et al. 2014; Omrani et al. 2014; Davini et al. 2015; Yamamoto and Palter 2016; Ruprich-Robert et al. 2017).

Despite its significance, the exact origin of the AMO is far from settled. While the potential role of the external forcings in pulsing the AMO signal has previously been suggested (Otterå et al. 2010; Booth et al. 2012), a number of modeling studies have illustrated that the AMO emerges internally as a SST manifestation of the heat convergence associated with Atlantic meridional overturning circulation (AMOC) in the absence of the variability in the external forcings (Delworth et al. 1993; Latif et al. 2004; Knight et al. 2005; Yan et al. 2018). Furthermore, in the observational records, Knudsen et al. (2011) found a persistent oscillation in the paleoclimatic reconstructions for the past 8000 years, while McCarthy et al. (2015a) have shown that the phase of the AMO sensitively responds to the ocean circulation in a centurylong sea level observational record from tide gauges along the east coast of the United States. The part of the 
AMO signature that is likely internally driven and linked to the AMOC variability, however, appears to be limited to the subpolar part of the AMO horseshoe pattern (e.g., Terray 2012; Zhang 2008). Its tropical counterpart, in contrast, often referred to as the "tropical arm," has been suggested to emerge as a result of the radiative feedback due to the warming by the shortwave radiation associated with shallow convection, arising as a lagged response to the subpolar SST anomaly (Yuan et al. 2016; Brown et al. 2016). These studies thus point toward the importance of the ocean dynamics as well as the subsequent atmospheric feedback in generation of the coherent SST signal over the North Atlantic basin.

In contrast to the aforementioned notion, a study by Clement et al. (2015) showed that the horseshoe SST pattern analogous to the AMO signal can be produced solely with the atmospheric stochastic forcing using slab ocean models from phase 3 of the Coupled Multimodel Intercomparison Project (CMIP3), without the ocean dynamics coming into play. O'Reilly et al. (2016) and Zhang et al. (2016) disputed this finding by arguing that this AMO-like SST pattern in the slab ocean models is not a consequence of the same mechanisms as the fully coupled counterparts. They showed that, for the case of the AMO positive phase, while the horseshoe pattern in slab ocean models arises due to the warming by the turbulent heat fluxes, the turbulent heat fluxes in fully coupled models act to cool the subpolar North Atlantic and instead the SST is warmed by the ocean dynamics. This result from the coupled climate models is consistent with the observational study by Gulev et al. (2013), who, with the use of a century-long observed turbulent heat flux dataset, revealed that on decadal and longer time scales the turbulent fluxes are upward in the midlatitude North Atlantic. Their study thus implies that the ocean is capable of actively driving the overlying atmosphere on decadal and longer time scales over this region, confirming the pioneering conjecture by Bjerknes (1964). Subsequent studies have discussed the relative roles of the atmosphere and the ocean (Clement et al. 2016; Cane et al. 2017; Garuba et al. 2018); however, reaching a consensus on the exact partitioning of their roles seems to be hindered due to the tightly coupled nature of the atmospheric and oceanic processes. In this study we will take a different approach based on the SST tendency equation in order to further our understanding of the mechanism behind the emergence of the AMO signal based on a state-of-the-art fully coupled climate model. In doing so, we take the varying ocean mixed layer depth into full consideration, which has been disregarded in previous studies.

Concurrently, a growing body of evidence indicates that a persistent positive phase of the leading mode of the atmospheric variability over the North Atlantic, the North Atlantic Oscillation (NAO), precedes both augmentation of the AMOC (Delworth and Greatbatch 2000; Eden and Willebrand 2001; Marshall et al. 2001; Visbeck et al. 2003; Delworth and Zeng 2016; Peings et al. 2016) as well as the northward shift and intensification of the Gulf Stream (Cessi et al. 2004; Nigam et al. 2018; McCarthy et al. 2018). NAO is characterized by a difference in the sea level pressure (SLP) field between the low pressure over Iceland and the high pressure over the Azores, and is associated with the modulation of the large-scale atmospheric circulation including the jet stream, the storm track, as well as the climate over the North Atlantic and its contiguous continents (e.g., Hurrell 1995; Marshall et al. 2001; Feldstein and Franzke 2017). While the intrinsic time scale of the NAO is about 10 days (Feldstein and Franzke 2017), a prominent low-frequency NAO variability has also been reported (Hurrell 1995; Curry and McCartney 2001; Omrani et al. 2014; Woollings et al. 2014). During the NAO positive phase, the anomalously strong westerlies advect the cold continental air over the oceanic deep convection sites, amplifying the buoyancy removal by the anomalous heat fluxes and deep water formation, thereby the persistent positive NAO likely acting to intensify the AMOC (Delworth and Zeng 2016). Several studies with coupled climate models have suggested that the intensified AMOC induces the AMO positive phase (Delworth et al. 1993; Latif et al. 2004; Knight et al. 2005; Yan et al. 2018). The AMO positive phase, in turn, has been shown to precede the negative phase of the NAO in both observational (Omrani et al. 2014; Peings and Magnusdottir 2014; Woollings et al. 2014; Yamamoto and Palter 2016) and modeling studies (Omrani et al. 2014, 2015; Davini et al. 2015; Peings et al. 2016; Ruprich-Robert et al. 2017). To explain this inverse relationship in the previous studies, two primary mechanisms have been put forth: Omrani et al. $(2014,2015)$ showed that this inverse relationship arises via stratosphere-troposphere dynamical coupling, thus necessitating the fully resolved stratosphere to simulate the process in a climate model. On the other hand, other studies attributed the emergence of the opposite-signed NAO primarily to the propagation of the atmospheric Rossby waves emanating from the tropical SST anomaly (Davini et al. 2015; Peings and Magnusdottir 2016; Peings et al. 2016).

Peings et al. (2016) have investigated this AMONAO link in a set of preindustrial control simulations of phase 5 of the Coupled Multimodel Intercomparison Project (CMIP5). They have found that a vast majority of the CMIP5 models underestimate the amplitude of the internal AMO signal, and that the subsequent lagged NAO-like response of the opposite sign is absent. Yan et al. (2018) attributed this suppression of the AMO amplitude to the subdued strength of the low-frequency AMOC variability, to which the amplitude of the AMO almost linearly responds in each CMIP3 and CMIP5 model. 
They further attributed the possible cause of this suppressed AMOC variability in turn to the modeled biases in the buoyancy fluxes. Thus, these studies suggest that most of the state-of-the-art coupled climate models are not capable of reproducing the multidecadal atmosphere-ocean phenomena, possibly as a consequence of the insufficient feedback from each phenomenon. This multidecadal feedback, in turn, crucially depends on the sufficient representation of each phenomenon. In particular, if this multidecadal feedback loop were to exist, it is hypothesized that the correct representation of the low-frequency NAO plays a key role, which is suppressed in majority of the current coupled climate models (Wang et al. 2017; Kim et al. 2018; O'Reilly and Zanna 2018).

The primary goal of the current study is to further our understanding of the origin of the AMO signal in the link from the NAO to the AMO, by employing the latest versions of a fully coupled model, MIROC6 (Tatebe et al. 2019). As will be shown later, MIROC6 is capable of representing both the AMO and the low-frequency NAO fairly well. Unlike previous studies that aimed at answering similar questions, our focus is not on understanding the exact partitioning of the oceanic and the atmospheric contributions to the formation of the AMO signal, but rather on apprehending how the ocean responds to the heat fluxes and changes in the ocean dynamics in forming the AMO signal. Provided the potential link between the low-frequency NAO and the AMO, our goal is also to understand the potential role of the low-frequency NAO in shaping the multidecadal SST signal. The focus of this work lies on the wintertime variability, when the NAO variability and therefore its impacts on the underlying ocean are the most dominant.

The rest of the paper is organized as follows. In section 2 we describe the model and datasets used, as well as the definition of the climate indices of interest. In section 3 we investigate the model fidelity compared to the observation, while in section 4 we identify the common band of frequencies for the climate indices of interest for each dataset using wavelet analysis and examine the multidecadal relationship among them. We analyze the role played by the heat fluxes and the ocean dynamics in generation of the AMO signal by carrying out a simple diagnostic based on a mixed layer temperature tendency budget in section 5 . In section 6 the importance of the NAO in emergence of the AMO signal is investigated. Discussion and conclusions are presented in section 7.

\section{Datasets and methods}

\section{a. MIROC6}

Our primary tool is version 6 of the Model for Interdisciplinary Research on Climate (MIROC6), a coupled climate model that has been cooperatively developed by a Japanese modeling community (Tatebe et al. 2019). MIROC6 has undergone a major update from its precedent version, MIROC5, where all the physical parameterizations of the submodules have been updated, and horizontal and vertical resolutions have been increased in both atmospheric and oceanic components. The atmospheric component is based on the CCSR-NIESFrontier Research Center for Global Change (FRCGC) atmospheric general circulation model (Numaguti et al. 1997), whose spectral resolution is T85 with 81 vertical levels, extending up to $0.004 \mathrm{hPa}$. The oceanic component is based on the CCSR Ocean Component Model (COCO; Hasumi 2000), and has a horizontal resolution of $1^{\circ}$ with 62 vertical levels, where the first 31 layers fall within the top $500 \mathrm{~m}$. Another major update from MIROC5 includes implementation of a parameterization scheme for shallow cumulus convection based on Park and Bretherton (2009). As a result, the reproducibility of the mean climate as well as the internal variability in MIROC6 has increased in comparison with MIROC5 (Tatebe et al. 2019).

In this study, as our interest lies in the natural climate variability without any anthropogenic influences, we use 500 years of the MIROC6's preindustrial control simulation, year 3200-3699, after the model spinup period (Tatebe and Watanabe 2018). Within these control simulations, the external forcing is set at the preindustrial level of year 1850 .

\section{b. Observational datasets}

We compare our modeled results with the following observational datasets. COBE-SST2 data (Hirahara et al. 2014) from 1850 to 2015 are used for the SST field, with a monthly temporal resolution and a $1^{\circ}$ spatial resolution over the whole globe. For the sea level pressure (SLP) field, we use HadSLP2r monthly dataset (Allan and Ansell 2006) also from 1850 to 2015, with a $5^{\circ}$ spatial resolution. The observational fields of the sea surface height (SSH) field and the three-dimensional temperature and salinity are from the monthly ARMOR3D REPv4 dataset for 1993-2010 with a 1/4 ${ }^{\circ}$ spatial resolution, which incorporates satellite and in situ observations through statistical methods (Guinehut et al. 2012).

\section{c. Definition of climate indices}

In this study, we define the NAO index as a wintertime [December-February (DJF)] leading empirical orthogonal function (EOF) of the SLP anomalies over the North Atlantic region, $20^{\circ}-70^{\circ} \mathrm{N}, 90^{\circ} \mathrm{W}-40^{\circ} \mathrm{E}$, following Hurrell et al. (2013). Since the maximum loading of the modeled SLP is not necessarily constrained to the observed location, this method is preferable over the conventional station-based definition of the NAO index. 
The AMO index is defined as a wintertime [JanuaryMarch (JFM)] 10-yr low-pass filtered, area-weighted mean SST over the North Atlantic basin (NASST; $\left.0^{\circ}-60^{\circ} \mathrm{N}\right)$, while we have also obtained fairly similar results using the DJF season (not shown). In addition, as was mentioned in the introduction, since studies suggest that the governing mechanisms of the warming over the subpolar and tropical parts of the AMO-associated SST may be different from each other (e.g., Zhang 2008; Terray 2012; Brown et al. 2016; Yuan et al. 2016), we also define the AMO index separately for these regions as in Ruprich-Robert et al. (2017), such that $\mathrm{AMO}_{\text {trop }}$ and $\mathrm{AMO}_{\text {subp }}$ are defined as an area-weighted mean SST over $0^{\circ}-28^{\circ} \mathrm{N}$ and $37^{\circ}-60^{\circ} \mathrm{N}$, respectively.

Lastly, we define the AMOC index as the maximum transport of the annual-mean meridional overturning streamfunction in the Atlantic sector over $500-5000 \mathrm{~m}$ at $20^{\circ}-50^{\circ} \mathrm{N}$.

Before computing these indices, in order to remove either the global warming trend in observation or the time tendency in the modeled outputs, SLP, SST, and the overturning streamfunction are detrended by following Ting et al. (2009). Namely, we remove the regression of these two-dimensional fields on the time series of their global averages from the total field. Note that since the modeled output is free of anthropogenic warming and the period we focus is after the spinup time, this detrending does not have any significant impact on the modeled output. In addition, each of these indices is normalized by its own one standard deviation in order to make them comparable among different datasets and variables.

\section{d. Statistical significance test}

We have estimated the statistical significance of our results with a Monte Carlo method, in which we generate 1000 first-order autoregressive surrogate time series and create a probability distribution by regressing the fields of interest on the band-passed surrogate time series. The confidence level is then determined by the relative position of the actual regression coefficients in the probability distribution created with the surrogate time series.

\section{Modeled fields}

The mean modeled AMOC for MIROC6, represented as an annual-mean meridional streamfunction, shows that the maximum value is found at around $40^{\circ} \mathrm{N}$ (Fig. 1a). As is described in Tatebe et al. (2019), the transport across $26.5^{\circ} \mathrm{N}$ in MIROC6 agrees fairly well with the observed estimate, with the mean AMOC in both datasets having the magnitude of $17.2 \mathrm{~Sv}(1 \mathrm{~Sv} \equiv$ $10^{6} \mathrm{~m}^{3} \mathrm{~s}^{-1}$; McCarthy et al. 2015b).
The climatological modeled SSH and mixed layer depth (MLD) in March, defined as the depth at which a change from the surface density of 0.125 is attained, are compared to their observed counterparts in Fig. 1b. The modeled mean wintertime MLD (color shading) and the deep convection sites (areas encircled with red contours) in MIROC6 agree reasonably well with the observation both in depth and location, with the deepest MLD found over the Labrador, Irminger, and Greenland-IcelandNorwegian Seas (Fig. 1b). In MIROC6, however, both the climatological Labrador Sea MLD as well as its deep convection site elongate more to the south (up to around $50^{\circ} \mathrm{N}$ ) along the rim of the Grand Banks compared to the observation, in which the southernmost deep MLD over the Labrador Sea only extends to around $55^{\circ} \mathrm{N}$. The modeled SSH field also compares reasonably well with the observation. When we infer geostrophic currents from the SSH field, however, it is evident that the modeled Gulf Stream and its extension are aligned more zonally than the observed path, as is the case with many other climate models (e.g., Griffies et al. 2015).

The spatial patterns of the SLP field regressed on the NAO index in both datasets also compare well with each other, exhibiting a clear dipole structure (Fig. 2). A closer look at the SLP spatial pattern, however, reveals that the modeled low SLP center is slightly shifted to the southwest compared to the observation, while the simulated high pressure center appears to be better aligned with the observed, suggesting a slight shift in the atmospheric wind associated with the NAO in the model compared to the observation.

The SST spatial pattern regressed onto the AMO index in MIROC6 and observation exhibits the typical horseshoe pattern (Fig. 3). The locations over which the maximum loading occurs, nonetheless, slightly differ in each dataset, although the small maximum over the Labrador Sea seems to be a common feature. The so-called tropical arm in MIROC6 is shifted more to the north compared to the observation, although the amplitude in MIROC6 is consistent with the observation. Additionally, it is also evident that MIROC6 shows an anomalously cold SST around $40^{\circ} \mathrm{N}, 45^{\circ} \mathrm{W}$, while the observation does not display such a feature. This cold SST anomaly seems to appear in other CMIP models (Peings et al. 2016) and since the location of this feature coincides with where the models fail to reproduce the observed northward extension of the Gulf Stream (Fig. 1b), it is suspected to be associated with the common model error in the Gulf Stream alignment.

Thus, overall, MIROC6 seems to well capture both the mean and the anomalies of the observed climate fields of interest. For a detailed comparison of the modeled fields to observations of more aspects of the climate, readers are referred to Tatebe et al. (2019). 

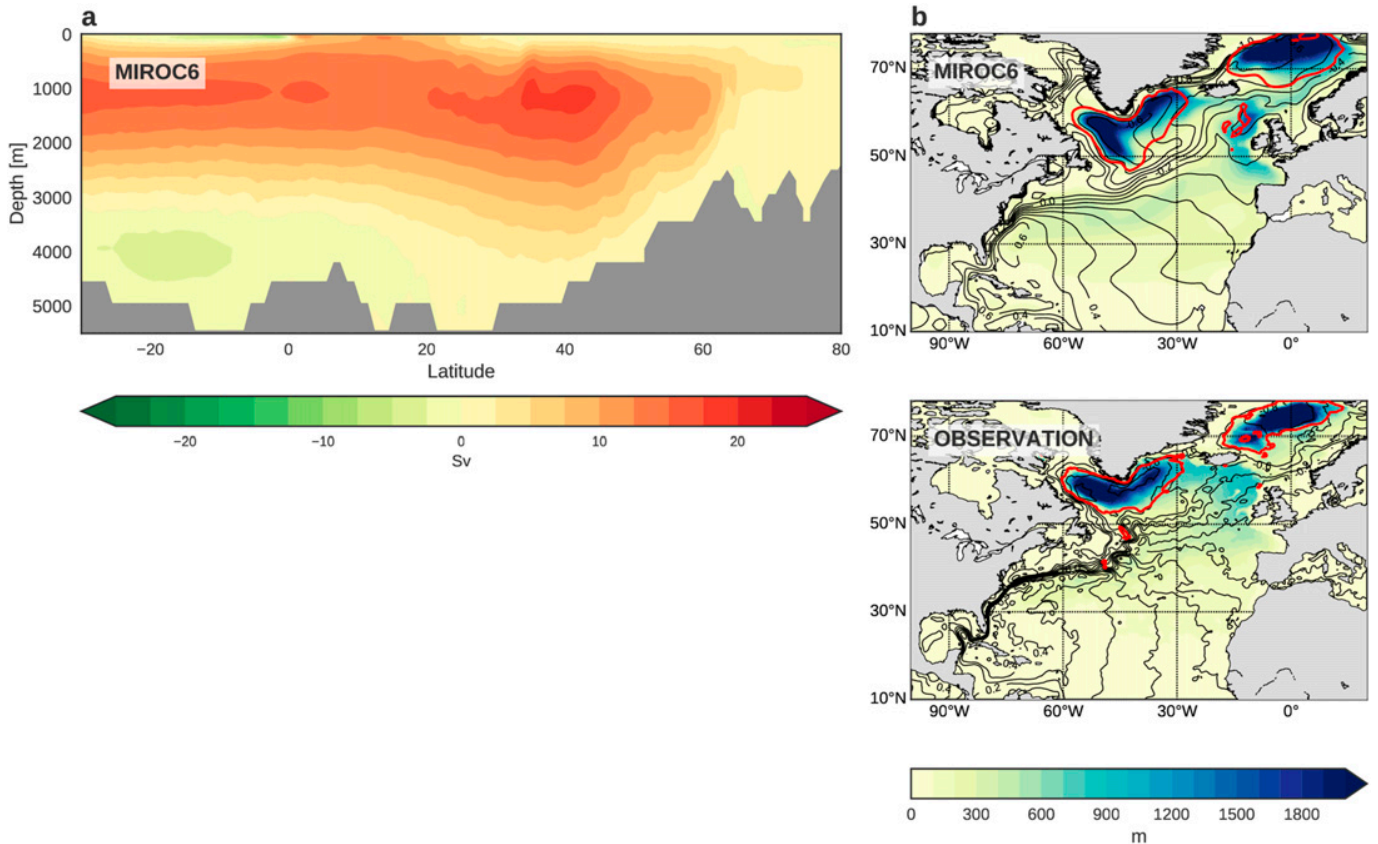

FIG. 1. (a) Annual-mean meridional streamfunction (Sv) over the Atlantic basin for MIROC6. (b) Wintertime sea surface height (SSH; black contour lines; $\mathrm{m}$ ) and mixed layer depth (shading; $\mathrm{m}$ ) for (top) MIROC6 and (bottom) observation. From both the observed and the modeled SSH datasets the global mean SSH value is subtracted in order to make them comparable. The contour interval of the SSH field is $0.1 \mathrm{~m}$. The convection regions are encircled with red contours, where the standard deviation of the wintertime mixed layer depth exceeds $300 \mathrm{~m}$ following Msadek and Frankignoul (2009).

\section{Relationship among three climate indices}

\section{a. Wavelet analysis}

Previous works have identified the dominant multidecadal signal in the observed AMO and NAO for the frequency band of approximately 55-90 years (e.g., Omrani et al. 2014). In a preindustrial control simulation of a coupled climate model, however, dominant frequency bands in the model do not necessarily coincide with those of the observed. This deviation could arise
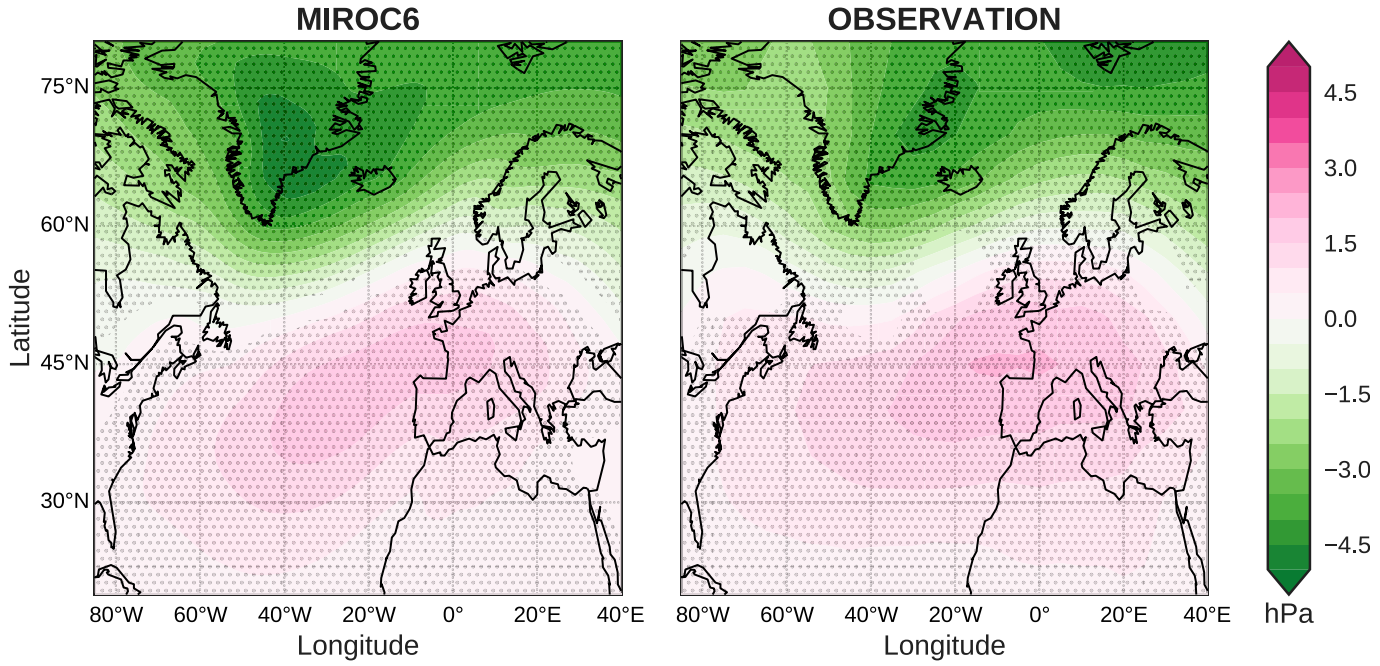

FIG. 2. Wintertime (DJF) sea level pressure (SLP) regressed onto the NAO index for (left) MIROC6 and (right) observation. Stippling indicates where it is statistically significant at the $95 \%$ level. 

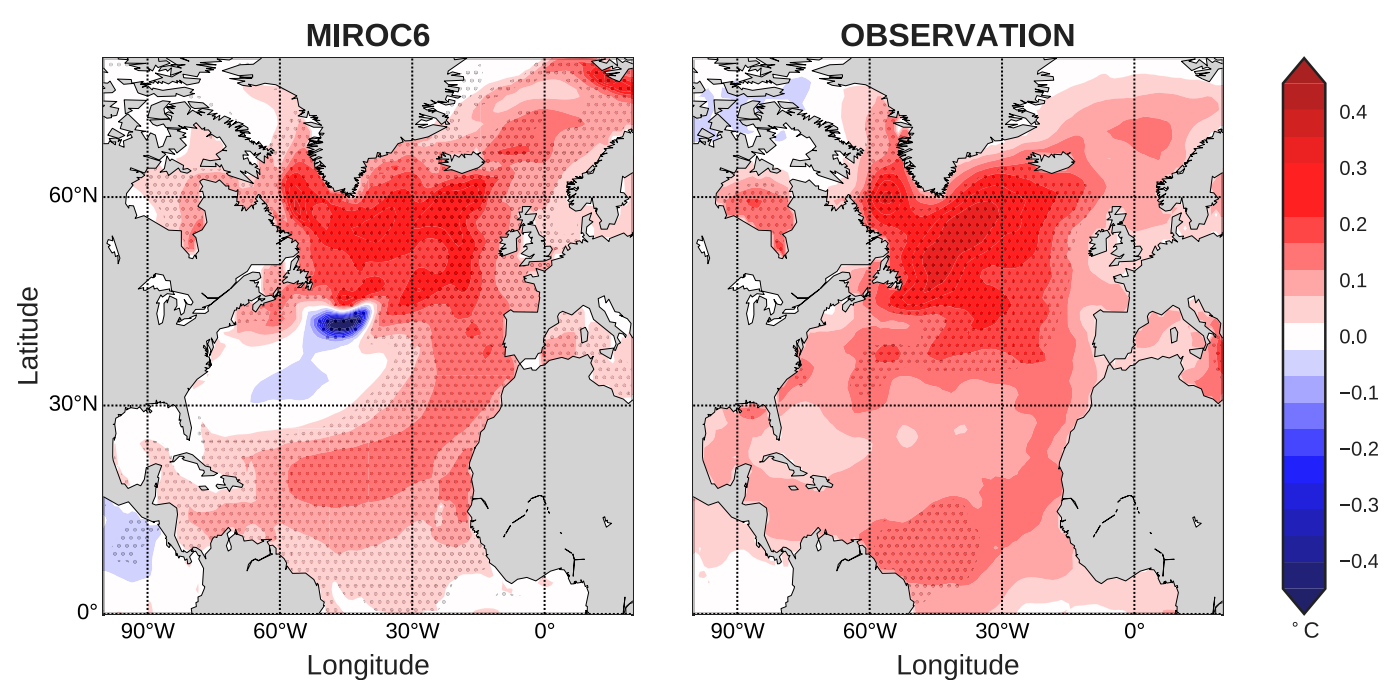

FIG. 3. Regression pattern of the monthly sea surface temperature (SST) anomalies $\left({ }^{\circ} \mathrm{C}\right)$ on the AMO index for (left) MIROC6 and (right) observation. Stippling indicates where it is statistically significant at the $95 \%$ level.

since, unlike the current climate, these control simulations are not constrained by the external forcings, which may act to pace the climate signals (Otterå et al. 2010; Booth et al. 2012). Thus, in order to identify a common multidecadal frequency band across all the climate indices of interest within each dataset, we apply the wavelet transform (Torrence and Compo 1998) with Morlet wavelet bases for each climate index defined in section 2c. Note that for the wavelet analysis of the AMO index, we use NASST before applying a lowpass filtering, in order to consider its full temporal spectrum.

A wavelet analysis (Fig. 4) suggests that, in observational datasets, there exists a prominent multidecadal frequency band that exhibits statistically significant power for both AMO and NAO, at around 55-90 years (enveloped by the black dashed lines in the figure), in agreement with the previous studies (Omrani et al. 2014). It is evident that there are also some other shorter frequency bands with statistically significant powers for both indices, but the signals are much weaker and less persistent compared to those on the multidecadal time scale. The powers found in MIROC6 for both AMO and NAO, in contrast, appear to be more scattered in comparison to the observed, displaying multiple bands of frequency with statistically significant powers in all indices. In MIROC6, the oceanic indices, $\mathrm{AMO}$ and $\mathrm{AMOC}$, tend to exhibit strong powers at multiple low-frequency bands, while the NAO shows a clear dominant peak with significant power on a multidecadal time scale at $40-70$ years (enveloped by the black dashed lines in Fig. 4). At this multidecadal frequency band, AMO and AMOC also exhibit a persistent signal, indicating that there possibly exists a multidecadal air-sea coupling of our interest at this frequency band.

\section{b. Time dependence of the AMO tropical arm signal}

For both model output and the observation, it is also apparent in Fig. 4 that the tropical SST signature, $\mathrm{AMO}_{\text {trop, }}$ does not have a strong multidecadal signal. As for MIROC6 there exists some multidecadal tropical signal, but it is not statistically significant; rather, it is evident that much of the multidecadal AMO signal actually stems from the subpolar part of the North Atlantic SST, $\mathrm{AMO}_{\text {subp }}$. In observation, $\mathrm{AMO}_{\text {trop }}$ exhibits three weak but dominant multidecadal frequency bands; the most dominant, persistent signal is found around the period of 100 years, while signals over the shorter time scales emerge as the time progresses. When combined with the subpolar region to obtain the basinwide, conventional AMO index, this signature of multiple powers in observation disappears, swamped by the subpolar signature, which is much more prominent. The $\mathrm{AMO}_{\text {trop }}$ 's longest frequency band, however, slightly shifts where the total AMO gains its maximum to a longer period.

Together, these results suggest that the conventional low-pass filtering to define the AMO index over the whole North Atlantic basin may falsely put together processes that occur on different time scales for the extratropical and the tropical regions, making it appear that the warming occurs over the entire North Atlantic basin coherently on all time scales longer than 10 years.

By contrast, $\mathrm{AMO}_{\text {subp }}$ exhibits more coherent signals on the multidecadal time scale, which agrees well with the AMOC wavelet powers. This result is in agreement with the previous studies, which suggest that the variability in the AMOC strength is concomitant with the subpolar 

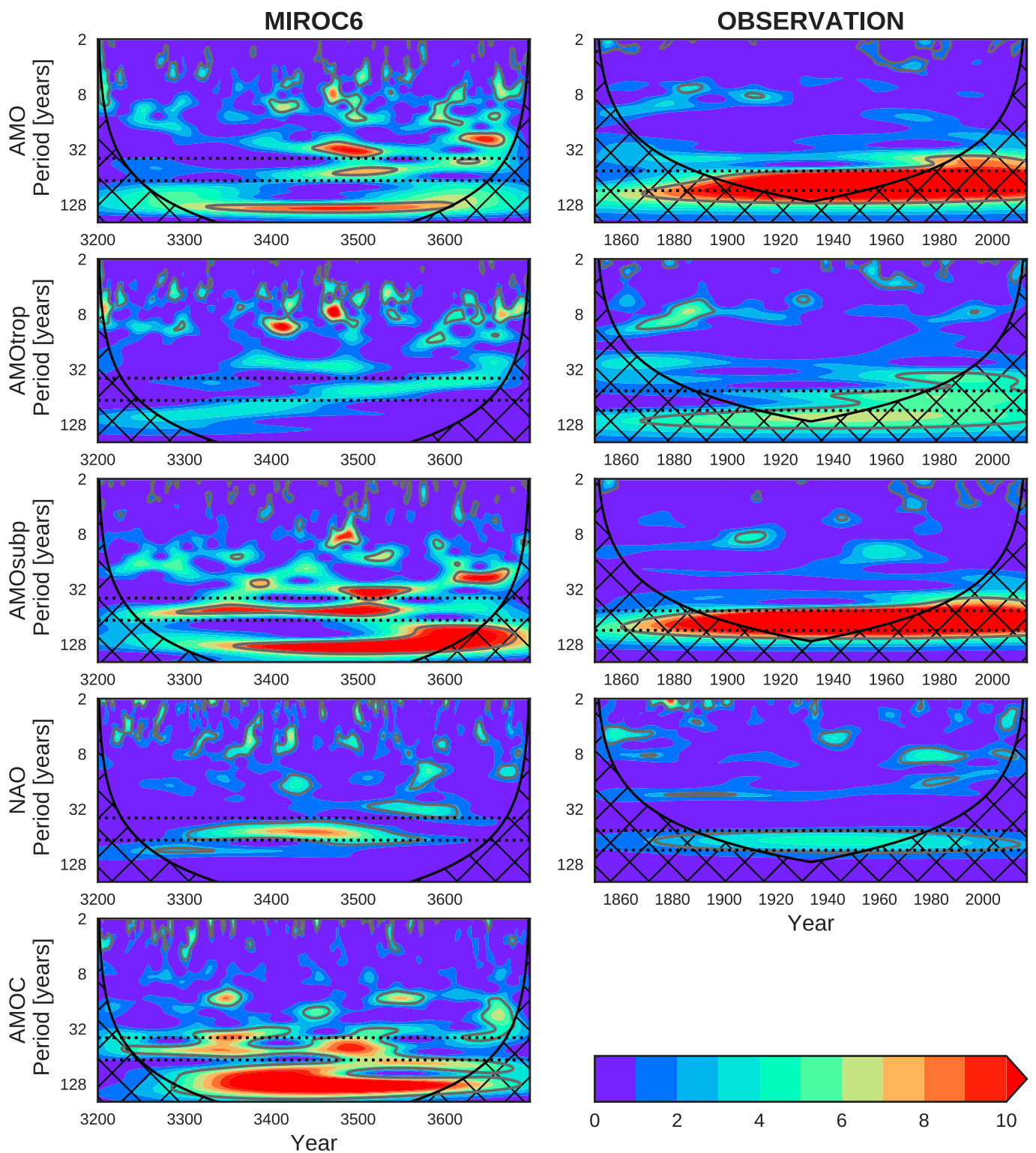

FIG. 4. Wavelet power spectrum of (first row) NASST (labeled as “AMO” but without a 10-yr low-pass filtering), (second row) NASST over the tropical region of $0^{\circ}-28^{\circ} \mathrm{N}$ (labeled as " $\mathrm{AMO}_{\text {trop" }}$ " but without a 10 -yr low-pass filtering), (third row) NASST over the subpolar region of $37^{\circ}-60^{\circ} \mathrm{N}$ (labeled as "AMO subp" but without 10 -yr lowpass filtering), (fourth row) the NAO index, and (fifth row) the AMOC index, for (left) MIROC6 and (right) observation. Each index is normalized by its standard deviation. The frequency bands where the signal is significant at the $90 \%$ level are enveloped with gray contours. The cutoff frequencies for the multidecadadal variability of interest are enveloped with the black dashed lines.

temperature variability (Zhang 2008; Terray 2012; Caesar et al. 2018). For this reason, we focus on the subpolar part of the AMO index, $\mathrm{AMO}_{\text {subp }}$, for the rest of the study.

\section{c. Lead-lag relationship among NAO, AMOC, and $A M O_{\text {subp }}$}

To elucidate the relationship among the NAO, AMOC, and $\mathrm{AMO}_{\text {subp }}$ in MIROC6 and observation, we extract the common band of multidecadal frequency for each dataset, which is enveloped by the black dashed lines in Fig. 4. The extracted multidecadal time series, 55-90 years for observation and 40-70 years for MIROC6, is shown in Fig. 5a. This operation of bandpass filtering is necessary, as the signal of each index is otherwise swamped by the higherfrequency variability, which has much larger amplitudes. Note that we have repeated the entire analysis by 

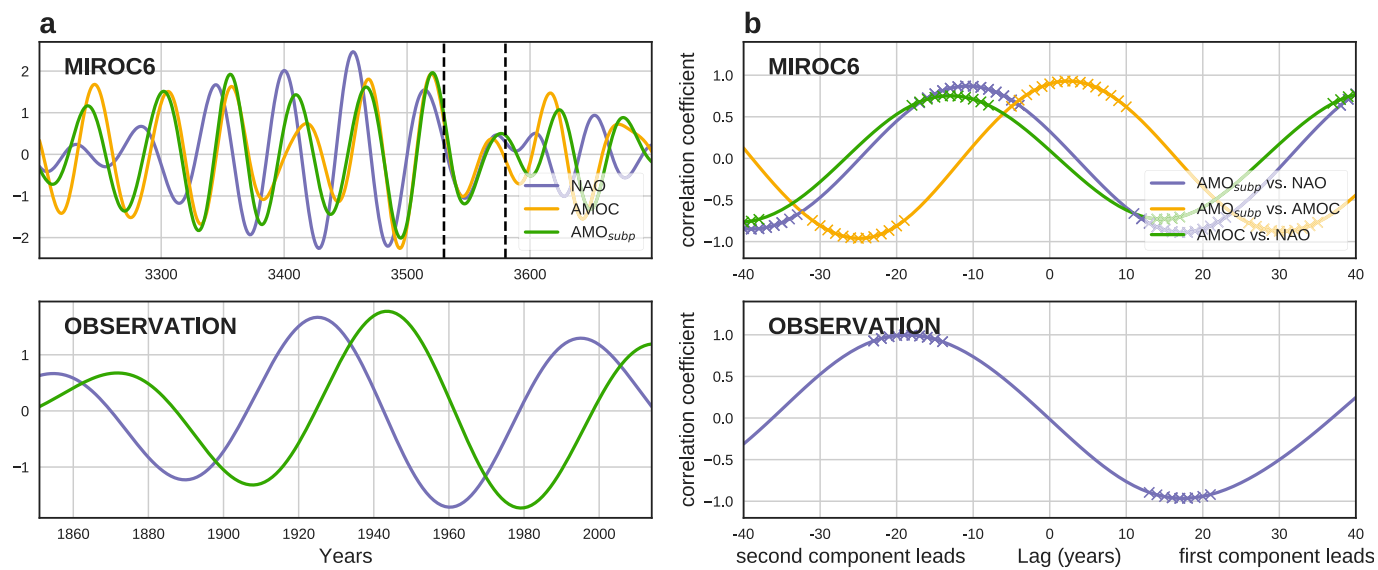

FIG. 5. (a) Time series of the multidecadal NAO, AMOC, and $\mathrm{AMO}_{\text {subp }}$ for (top) MIROC6 (for 40-70 years) and (bottom) observation (for 55-90 years). The black dashed lines for the top panel indicate the period when the possible regime shift occurs. (b) Lead-lag correlation of each extracted climate index with each other. While the whole period is used for the observation, years from 3200 to 3529 are used for MIROC6 to construct the figure for the reasons mentioned in the main text. The crosses indicate where the correlation is statistically significant at the $95 \%$ level. Each index is normalized by its standard deviation.

applying a 35-yr low-pass filtering instead of a bandpass filtering for MIROC6 and qualitatively the same results were obtained; however, with the low-pass filtering some signal becomes less apparent compared with the bandpass filtering, overwhelmed by the large lowfrequency oceanic variability $(>70 \mathrm{yr})$ noted earlier (not shown).

Observations exhibit a clear link between the extracted multidecadal NAO and $\mathrm{AMO}_{\text {subp }}$, such that the maximum of the persistent NAO positive phase leads the peak of $\mathrm{AMO}_{\text {subp }}$ by approximately 20 years, which is subsequently followed by the negative phase of the NAO (second row of Fig. 5b). A similar relationship between the two indices can be found in MIROC6, such that the persistent NAO always leads $\mathrm{AMO}_{\text {subp }}$ of the same sign (first row of Fig. 5b). MIROC6, however, seemingly undergoes a regime shift in the mid-3500s as evident in Fig. 5a. During the earlier period, the NAO positive peak leads the positive $\mathrm{AMO}_{\text {subp }}$ peak by about 10 years, which is then followed by the maximum AMOC intensification approximately after 5 years. This relationship is at odds with the previous studies, which suggests that the AMOC intensification leads the AMO positive peak (e.g., Delworth et al. 1993; Latif et al. 2004; Knight et al. 2005). In contrast, after the mid-3500s, AMOC intensification follows the NAO positive peak, which is then followed by the positive $\mathrm{AMO}_{\text {subp }}$ peak. The amplitude of the multidecadal climate indices during this later period drastically drops compared to the earlier period. This discrepancy from the previous studies for the earlier period mainly stems from the fact that here we use the $\mathrm{AMO}_{\text {subp }}$ index in place of the full AMO index that considers the whole North Atlantic basin. As we show later in section 5a, $\mathrm{AMO}_{\text {subp }}$ leads the full AMO approximately by 10 years; thus, the relationship among the climate indices of interest is in line with the previous studies when the full AMO index is considered. Note that it is not uncommon for a coupled climate model to go through such regime shifts. For instance, changes in the AMOC frequencies in a long model integration have been reported in the previous studies (e.g., Danabasoglu 2008; Delworth and Greatbatch 2000; Kwon and Frankignoul 2014). While conducting further analyses on the reasons behind this regime shift is outside the scope of the current study, we speculate that the reported change in the AMOC frequencies might be associated with a regime shift in the relationship among the multidecadal climate indices similar to our result.

For the above reasons, we focus on the multidecadal (40-70 years) variability in MIROC6 data from years 3200 to 3529 in the following analyses, during which we observe a significant multidecadal relationship among the climate indices of interest, similar to observation.

\section{Emergence of the North Atlantic basinwide warming}

In this section, in order to resolve the current controversy as to which processes are in play in generating the SST pattern associated with AMO, we conduct a simple diagnostic based on the mixed layer heat budget, which enables us to separate the role played by the surface heat fluxes and the ocean dynamics in creating the multidecadal SST pattern. As stated in the introduction, unlike 

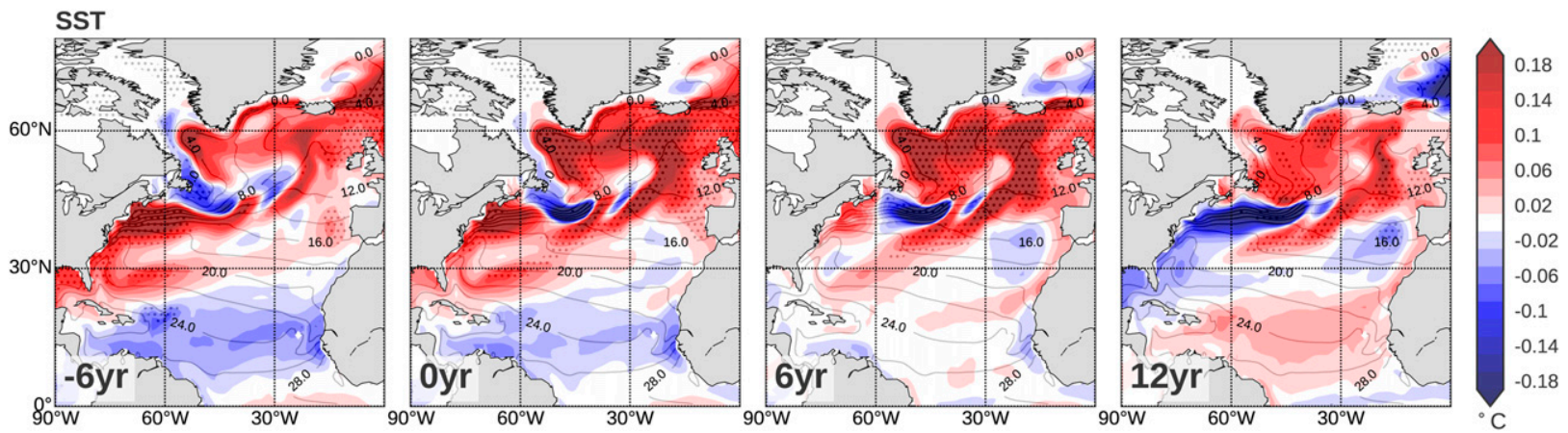

FIG. 6. Wintertime (JFM) SST field $\left({ }^{\circ} \mathrm{C}\right)$ lag regressed on the multidecadal (40-70-yr frequency band) $\mathrm{AMO}_{\text {subp }}$ index (shading), overlaid on the wintertime SST climatological values (gray contours) for MIROC6. Stippling indicates where the anomalies are statistically significant at the $95 \%$ level.

previous studies, our goal is not to partition the role played by the atmosphere and the ocean; rather, we are interested in apprehending how the ocean responds to the given heat fluxes and the changes in the ocean dynamics. We start the analysis by first investigating how this SST pattern evolves in the following subsection.

\section{a. Evolution of the multidecadal NASST pattern}

The NASST lag-regressed on the $\mathrm{AMO}_{\text {subp }}$ index extracted for the multidecadal frequency band of 40-70 years is shown in Fig. 6. It is evident from the figure that in MIROC6 the subpolar North Atlantic warming leads the tropical North Atlantic warming by approximately 10 years. Thus, the so-called AMO horseshoe pattern where the coherent anomalous warming/cooling over both regions of the Atlantic basin emerges also takes place about 10 years after the warmest/coldest subpolar gyre is attained.

It is notable that before the subpolar gyre warming, the Gulf Stream, whose location is denoted by the tightly packed isotherms (black contours), becomes anomalously warmer (lag -6 and 0 years in Fig. 6). This warming, however, gradually diminishes, until the warm anomaly is replaced by the cold anomaly at around lag 12 years. At this point, the extratropical North Atlantic displays the spatial pattern that is somewhat analogous to the so-called AMOC fingerprint. The AMOC fingerprint consists of the subpolar gyre warming and the Gulf Stream cooling, and it has been suggested that this spatial pattern is indicative of the AMOC intensification (Zhang 2008; Caesar et al. 2018). We will further investigate the role of the Gulf Stream in creating this AMO-associated SST pattern later in section $6 \mathrm{~b}$.

\section{b. Partition of the total SST tendency}

The tendency of the ocean temperature in the mixed layer can be expressed as

$$
\frac{\partial T}{\partial t}=\frac{\partial \mathrm{SST}}{\partial t}=\frac{Q_{\text {net }}}{\rho c_{p} H}+\text { oceanic terms }
$$

where $T$ is the mixed layer temperature (equal to SST; Deser et al. 2010); $Q_{\text {net }}$ is the net surface heat flux (positive downward), which is the sum of sensible heat flux (SH), latent heat flux (LH), surface longwave (LW) radiation, and surface shortwave (SW) radiation; $c_{p}$ is the specific heat of seawater $\left(=3990 \mathrm{~J} \mathrm{~K}^{-1} \mathrm{~kg}^{-1}\right) ; H$ is the wintertime MLD; and $\rho$ is the surface density of seawater (Qiu and Kelly 1993; Yasuda et al. 2000; Morioka et al. 2010). With this formulation where the properties are vertically averaged in the mixed layer, there is no need for evaluating the strong vertical mixing found in the mixed layer.

To quantify the relative roles played by the heat fluxes and the ocean, we first partition Eq. (1) as follows:

$$
\begin{aligned}
& \frac{\partial \mathrm{SST}_{\mathrm{hflx}}}{\partial t} \equiv \frac{Q_{\mathrm{net}}}{\rho c_{p} H}, \\
& \frac{\partial \mathrm{SST}_{\mathrm{ocn}}}{\partial t} \equiv \frac{\partial \mathrm{SST}_{\text {total }}}{\partial t}-\frac{\partial \mathrm{SST}_{\mathrm{hflx}}}{\partial t} .
\end{aligned}
$$

In Eq. (2), $\partial \mathrm{SST}_{\mathrm{hflx}} / \partial t$ represents the part of the SST tendency due to the surface heat fluxes, whereas $\partial \mathrm{SST}_{\mathrm{ocn}} / \partial t$ in Eq. (3) is the part explained by the oceanic processes. Note that, as shown in Eq. (3), the $\partial \mathrm{SST}_{\mathrm{ocn}} / \partial t$ term is simply a residual from the total SST tendency, $\partial \mathrm{SST}_{\text {total }} / \partial t$. This residual term therefore includes not only heat convergence and entrainment but also diffusion, detrainment, and other high-frequency oceanic processes, and we discuss this term in more detail later in section 5e. By treating the oceanic processes as a residual, the total SST tendency is by necessity the sum of the term due to the heat fluxes and that due to the oceanic processes. Note also that we fully acknowledge the fact that the turbulent heat fluxes, which are the addition of the sensible and latent 

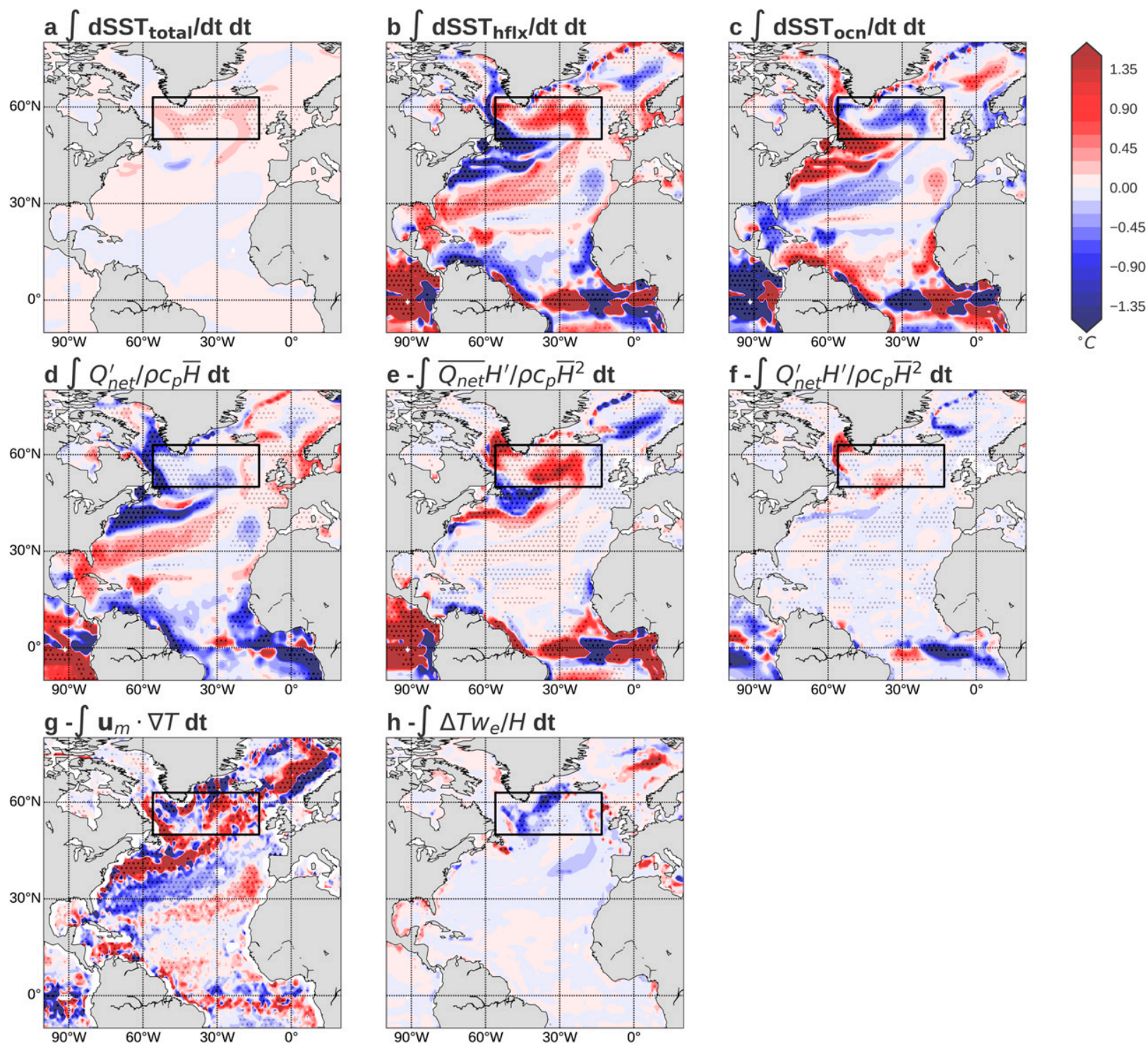

FIG. 7. SST tendency terms, integrated from the year when $\mathrm{AMO}_{\text {subp }}$ is minimum to the year when $\mathrm{AMO}_{\text {subp }}$ is maximum $\left({ }^{\circ} \mathrm{C}\right)$. (top) Decomposition of (a) the total SST tendency term into (b) the term due to the heat flux and (c) the ocean term, following Eqs. (2) and (3). (middle) Decomposition of the SST tendency term due to the heat fluxes into the terms due to (d) the anomalous heat fluxes, (e) the anomalous mixed layer depth, and (f) the cross product of the anomalous heat fluxes and mixed layer depth, following Eq. (4). (bottom) Decomposition of the SST tendency due to the ocean terms into the term due to $(\mathrm{g})$ the heat advection and $(\mathrm{h})$ the entrainment. The black box in each panel envelops the subpolar region of interest. Stippling indicates where the anomalies are statistically significant at the $95 \%$ level.

heat fluxes, are the products of both the atmospheric and oceanic properties. While the atmospheric stochastic forcings explain much of the subdecadal variability in the turbulent heat fluxes, the variation in SST plays an important role on a longer time scale (Gulev et al. 2013; Yamamoto et al. 2015). In this study, however, we will investigate how the ocean responds to given heat fluxes and not how the heat fluxes are exactly partitioned into the atmosphere and the ocean. In computing Eqs. (2) and (3), our goal is to investigate the determining factors for the SST during wintertime when the NAO variability is the most prominent. For this reason, we set the SST value to be of wintertime, while the net surface heat flux to be that of the annual mean, which gives rise to the SST difference from one winter to the other. Furthermore, we use the deepest MLD of the two consecutive years, which reflects the maximum ocean heat capacity for each year, in order to account for the full effect of the convective vertical mixing within the MLD. 

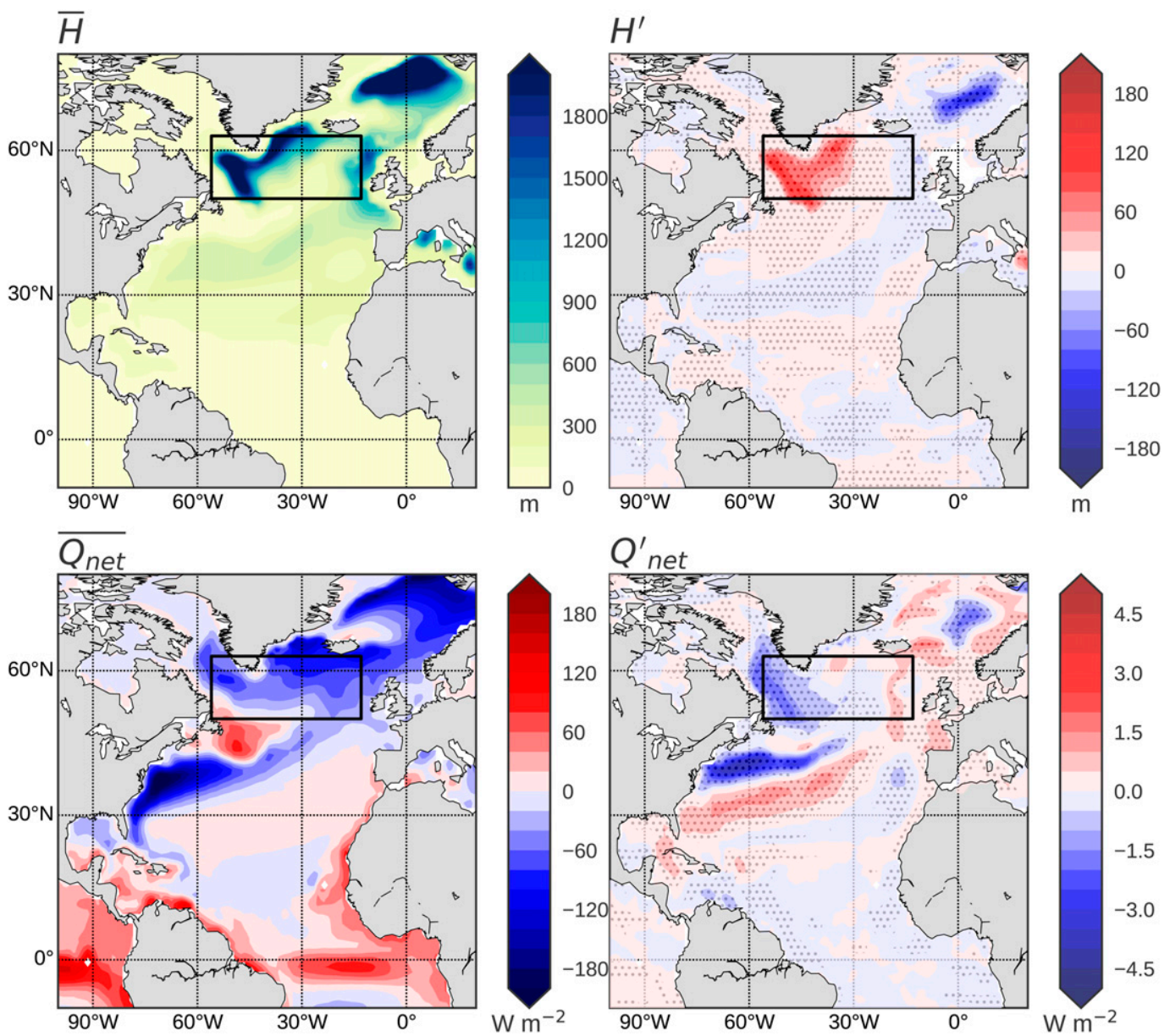

FIG. 8. (top left) Wintertime (JFM) climatological mixed-layer depth (m) and (top right) wintertime anomaly of the mixed layer depth $(\mathrm{m})$ averaged over the year when $\mathrm{AMO}_{\text {subp }}$ is minimum and the year when $\mathrm{AMO}_{\text {subp }}$ is maximum. (bottom) As in the top panels, but for the heat fluxes $\left(\mathrm{W} \mathrm{m}^{-2}\right)$. The region encompassed with the black box in each panel is the subpolar gyre of interest. The sign convention of the heat fluxes in this figure is positive downward. Stippling indicates where the anomalies are statistically significant at the $95 \%$ level.

The total SST tendency in MIROC6 is shown in Fig. 7a. The figure exhibits the integration of the SST warming from the year when $\mathrm{AMO}_{\text {subp }}$ is minimum to the year when $\mathrm{AMO}_{\text {subp }}$ takes its maximum value, thereby showing the spatial pattern of the subpolar SST's maximum warming. Prior to this integration, each term is lag-regressed onto the extracted $\mathrm{AMO}_{\text {subp }}$ index. In agreement with Fig. 6, the maximum warming is found over the Atlantic subpolar region, which seemingly extends from the North Atlantic Current. This region also coincides with where the wintertime climatological MLD is fairly deep (Fig. 8). In the following analysis, we focus on this region where maximum loading of SST as well as the deep MLD are found, indicated with the thick black box on Fig. 7.

When we partition this total SST tendency into the part that is explained by the heat fluxes (Fig. 7b) and the part by the oceanic terms (Fig. 7c), an unexpected pattern emerges. The figure suggests that the heat fluxes are responsible for the warming over the subpolar gyre region, while the oceanic terms act to cool the region. The unexpectedness of this result is twofold: First, previous studies that attribute the AMO to the internal ocean circulation explain the AMO warming as a consequence of the ocean heat convergence (e.g., Delworth et al. 1993; Latif et al. 2004; Knight et al. 2005; Zhang et al. 2016; Kim et al. 2018). Following these results, therefore, one would anticipate that the total SST tendency would reflect that of the ocean term. Second, the subpolar gyre is a region where the turbulent heat fluxes are upward on a multidecadal time scale during the AMO positive phase, acting to cool this part of the ocean (Fig. 8) as is the case in observation (Gulev et al. 2013). Thus, this outcome of our analysis that the heat flux term is generating the relative warming is a perplexing result. 


\section{c. Partitioning of the SST tendency due to surface heat fluxes}

To understand the enigma of how the surface heat flux cooling leads to the SST warming, we further partition Eq. (2) into the part that is explained by the anomalous surface heat fluxes and the part by the anomalous MLD by following Morioka et al. (2010, 2012). To do so, we decompose these two variables of interest into their wintertime mean $\overline{()}$ and the deviation from it ()$^{\prime}$, such that $Q_{\text {net }}=\overline{Q_{\text {net }}}+Q_{\text {net }}^{\prime}$ and $H=\bar{H}+H^{\prime}$. The wintertime anomaly of Eq. (2) then can be approximated as follows, by expanding up to the second order of the Taylor expansion series, while safely assuming that the seawater density remains constant:

$$
\begin{aligned}
\left(\frac{\partial \mathrm{SST}_{\mathrm{hflx}}}{\partial t}\right)^{\prime} \equiv & \left(\frac{Q_{\mathrm{net}}}{\rho c_{p} H}\right)^{\prime} \approx \frac{Q_{\mathrm{net}}^{\prime}}{\rho c_{p} \bar{H}}-\frac{\overline{Q_{\mathrm{net}}} H^{\prime}}{\rho c_{p} \bar{H}^{2}} \\
& -\frac{Q_{\mathrm{net}}^{\prime} H^{\prime}}{\rho c_{p} \bar{H}^{2}} .
\end{aligned}
$$

In this formulation, the first term on the right-hand side explains the SST tendency due to the anomalous surface fluxes $Q_{\text {net }}^{\prime}$, the second term is due to the anomalous MLD $H^{\prime}$, and the last term is a product of both the anomalous MLD and the anomalous surface heat fluxes. Thus, this partition allows us to determine the relative contribution played by each of these anomalous terms. Note that, as was discussed in Morioka et al. (2010), since the variability of MLD is not small enough compared to the mean state of MLD (Fig. 8), the denominator cannot be expanded into a Taylor series.

The second row of Fig. 7 shows the result of this partitioning of the SST tendency term due to the surface heat fluxes. An unequivocal feature that stands out over the subpolar region is that it is the anomalous MLD, $H^{\prime}$, that is responsible for the warming we have observed for the SST tendency due to the heat fluxes (Fig. 7e). The North Atlantic is one of the very few regions where oceanic deep convection takes place, with the MLD fluctuation making up of approximately $30 \%$ of its mean, the latter of which is fairly deep compared to the rest of the ocean (Fig. 8). The warming phase of the subpolar North Atlantic coincides with the time period when the region undergoes further deepening of the MLD (Fig. 9, left top vs middle panels). Note that the region off the shore of Newfoundland where a model bias in the MLD is seen in Fig. $1 \mathrm{~b}$ does not exhibit a strong signal in Fig. 7e, and therefore we speculate that the bias does not have a significant consequence. In contrast to the anomalous MLD, the anomalous heat flux $Q_{\text {net }}^{\prime}$ is relatively small compared to its mean, with both the mean and the anomaly acting to cool the subpolar region on this multidecadal time scale when the subpolar gyre is warm (Fig. 8), in agreement with previous studies (Gulev et al. 2013; Yamamoto et al. 2015). The cross product of the anomalous terms, $Q_{\text {net }}^{\prime} H^{\prime}$ (Fig. 7f), has a negligible effect on the subpolar SST. Overall, our results suggest that the SST warming over the North Atlantic subpolar gyre due to the heat fluxes $\left(\partial \mathrm{SST}_{\mathrm{hffx}} / \partial t\right)$ seen in the previous section is a consequence of the competition between the warming due to the deeper MLD and the cooling by the surface heat fluxes. This result implies that deepening of the MLD increases the surface ocean heat capacity such that the ocean is less susceptible for the cooling by the surface heat fluxes, resulting in the relative warming. This effect of the MLD variability has not been addressed in the previous studies, where MLD is assumed to be invariant (Clement et al. 2016; Zhang et al. 2016; Cane et al. 2017; Garuba et al. 2018).

\section{d. Dependence of the factors influencing different regions}

Next, we partition the SST tendency as was done in the previous sections, but separately for the subpolar (indicated by the black contours on Fig. 7) and the tropical $\left(0^{\circ}-28^{\circ} \mathrm{N}\right)$ North Atlantic.

The left panels of Fig. 9 confirm our findings in the previous section, such that the SST tendency associated with the AMO signal $\left(\partial \mathrm{SST}_{\text {total }} / \partial t\right)$ over the subpolar region is primarily explained by the SST tendency term associated with the heat fluxes $\left(\partial \mathrm{SST}_{\mathrm{hfl}} / \partial t\right)$, opposing the cooling by the oceanic terms $\left(\partial \mathrm{SST}_{\mathrm{ocn}} / \partial t\right.$; top-left panel). This SST warming due to heat fluxes is predominantly made up of a balance between the term due to the anomalous MLD, which is acting to warm, and the term due to the anomalous heat fluxes, which is acting to cool (middle-left panel). This cooling by the anomalous heat fluxes is largely associated with the anomalous latent heat fluxes (bottom-left panel).

The tropical part of the North Atlantic SST tendency, in contrast, unveils a fairly dissimilar picture (Fig. 9, right panels). The total SST tendency ( $\left.\partial \mathrm{SST}_{\text {total }} / \partial t\right)$ for this region is a result of a close-tied competition between the term due to the heat fluxes $\left(2 \mathrm{SST}_{\mathrm{hffx}} / \partial t\right)$, which is acting to warm, and the term due to the ocean $\left(\partial \mathrm{SST}_{\text {ocn }} / \partial t\right)$, which is acting to cool. These two opposing terms are at work almost synchronously, and the resultant SST tendency is fairly small (top-right panel). Unlike the subpolar region, where the anomalous MLD is responsible for most of the warming, it is the anomalous heat fluxes that dominate the warming over the tropical region (middle-right panel). This contrast from the subpolar region is consistent with the fact that the MLD over the tropical region is much shallower with smaller variability compared to the subpolar counterpart, making the part of 


\section{Subpolar}
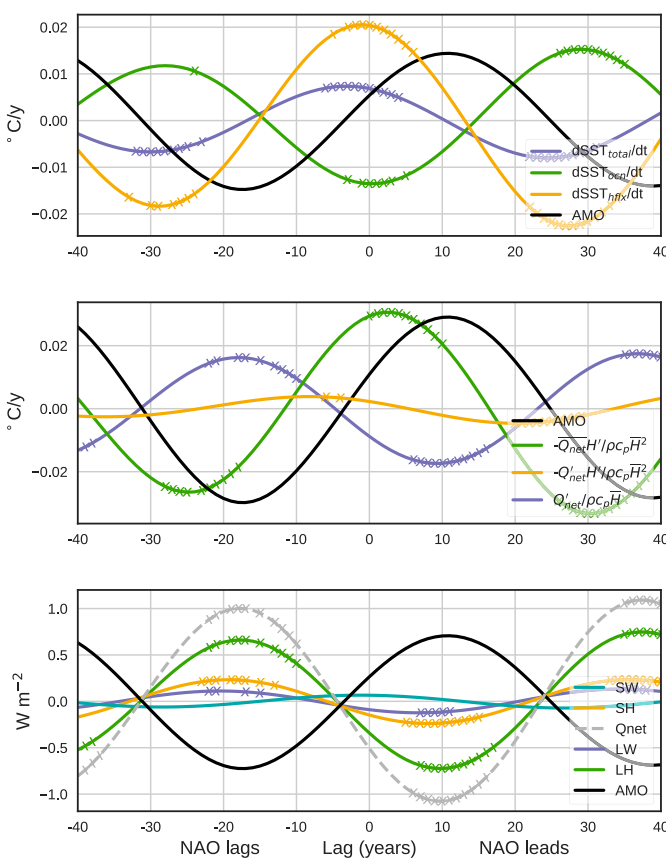

Tropics
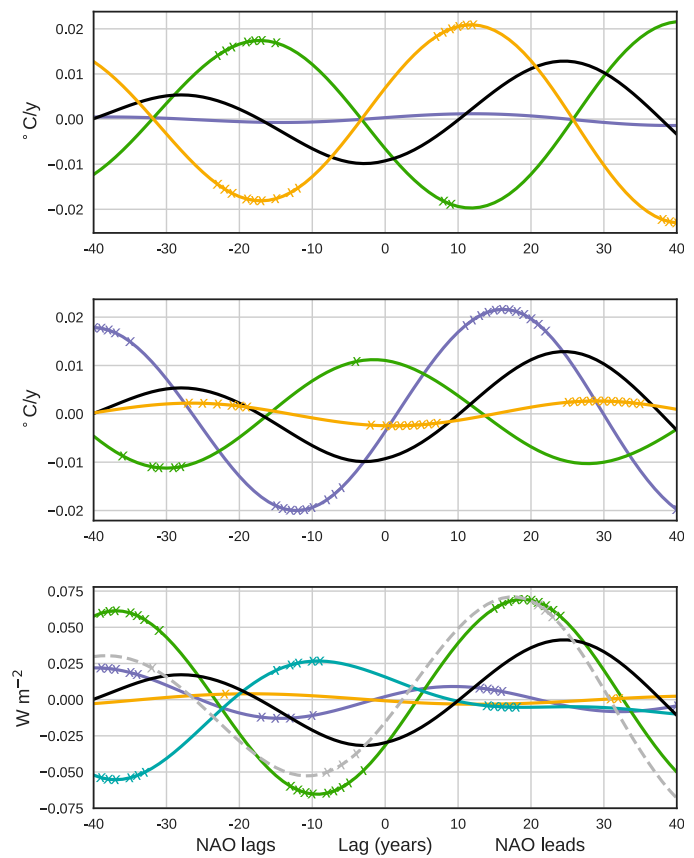

FIG. 9. (top) Lag regression of each term making up of the total SST tendency term $\left({ }^{\circ} \mathrm{C} \mathrm{yr}^{-1}\right)$ following Eqs. (2) and (3) on the multidecadal NAO index: $d \mathrm{SST}_{\text {total }} / d t$ in purple, $d \mathrm{SST}_{\mathrm{ocn}} / d t$ in green, and $d \mathrm{SST}_{\mathrm{hflx}} / d t$ in yellow, for (left) the subpolar and (right) the tropical region. (middle) As in the top panels, but for the terms that comprise the SST tendency due to heat fluxes following Eq. (4), $-\overline{Q_{\text {net }}} H^{\prime} / \rho c_{p} \bar{H}^{2}$ in green, $Q_{\text {net }}^{\prime} / \rho c_{p} \bar{H}$ in purple, and $-Q_{\text {net }}^{\prime} H^{\prime} / \rho c_{p} \bar{H}^{2}$ in yellow. (bottom) As in the top panels, but for the different heat flux terms that make up the anomalous heat fluxes $\left(\mathrm{W} \mathrm{m}^{-2}\right.$; purple line in the middle panels): sensible heat flux in yellow, latent heat flux in green, shortwave radiation in cyan, longwave radiation in purple, and the net heat flux in gray. The black line in each panel denotes the normalized AMO index, but is the $\mathrm{AMO}_{\text {subp }}$ index for the subpolar panels (standard deviation of $0.031^{\circ} \mathrm{C}$, as opposed to $0.041^{\circ} \mathrm{C}$ in the observation) and $\mathrm{AMO}_{\text {trop }}$ for the tropics (standard deviation of $0.016^{\circ} \mathrm{C}$, in comparison to $0.011^{\circ} \mathrm{C}$ in the observation), respectively. A region of the Labrador Current has been removed in computing the subpolar signal, where a different dynamics is in play. The crosses indicate where the anomalies are statistically significant at the $95 \%$ level.

the ocean more susceptible to the heat fluxes (Fig. 8). The partitioning of the heat fluxes into each term reveals that this anomalous heat flux is again dominantly explained by the latent heat fluxes (bottom-left panel). This result is somewhat incoherent with the previous studies, which suggested that it is the shortwave radiation associated with the low-level clouds that is responsible for the tropical warming (Brown et al. 2016; Yuan et al. 2016). In our analysis, shortwave radiation makes little contribution for the overall warming of the region.

\section{e. Ocean contribution to the SST tendency}

So far we have closely looked into the role played by the SST tendency term related to surface heat fluxes. However, a question remains as to what extent the ocean contributes to the SST tendency as has been shown in the previous studies (e.g., Delworth et al. 1993; Latif et al. 2004; Knight et al. 2005; Zhang et al. 2016; Kim et al. 2018), particularly given that our result suggests that the ocean acts to cool during the AMO positive phase. To reconcile these two seemingly inconsistent results, we further analyze the oceanic term by expanding it into the two dominant terms following Yasuda et al. (2000) and Morioka et al. (2012):

$$
\frac{\partial \mathrm{SST}_{\mathrm{ocn}}}{\partial t}=-\mathbf{u}_{m} \cdot \nabla T-\frac{\Delta T}{H} w_{e}+\text { res },
$$

where $\mathbf{u}_{m}$ is the mixed layer current velocity, $\Delta T$ is the temperature difference between the mixed layer and the layer below, and $w_{e}$ is the entrainment velocity. Further following Morioka et al. (2012), we define $\Delta T$ as the temperature difference between the sea surface and $20 \mathrm{~m}$ below the MLD base, whereas we calculate the entertainment velocity as

$$
w_{e}=\frac{\partial H}{\partial t}+\nabla \cdot \mathbf{u}_{m} H
$$

Thus, the first term of the right-hand side of Eq. (5) explains the contribution by the horizontal temperature 
advection, the second term is by the entrainment, which is in effect only during the periods when the MLD is deepening (i.e., $\partial H / \partial t>0$ ), and the last term, which is the residual term (res), includes diffusion and the other high-frequency terms.

The oceanic contributions to the SST tendency thus computed are shown on the third row of Fig. 7. Our result suggests that, in general, the horizontal heat advection (Fig. $7 \mathrm{~g}$ ) acts to warm the subpolar region, consistent with the previous studies (e.g., Zhang et al. 2016; Kim et al. 2018). A closer look at the figure, however, reveals that the warming by the horizontal heat advection over the subpolar gyre region is limited to the rim of the subpolar gyre and does not extend over the entire subpolar region. The figure further unveils that the entrainment term (Fig. 7h) acts to cool the region. This vertical effect has also not been taken into account in the previous studies, where the oceanic contribution was often considered to a fixed depth without taking into consideration of the variable MLD (e.g., Woollings et al. 2014; McCarthy et al. 2015a; Zhang et al. 2016). Our study thus suggests that, despite that the horizontal advection acts to generally warm the North Atlantic subpolar gyre as has been suggested by the previous studies, when the vertical component is also considered, the ocean in fact acts to cool the subpolar gyre.

\section{NAO impact on the ocean circulation}

Given that the persistent NAO leads the AMO of the same sign in both observation and in MIROC6 (Fig. 5), next we examine how the low-frequency NAO can possibly lead to the MLD deepening, which precedes the subpolar SST warming.

\section{a. Lag regression of the surface ocean fields onto the multidecadal NAO index}

Figure 10 illustrates the lag regression of the surface wind stress, surface wind stress curl, turbulent heat fluxes ( $\mathrm{SH}+\mathrm{LH}$, positive upward), and MLD on the multidecadal NAO index. The figure therefore shows how these fields develop with a progress in the lowfrequency NAO. As one expects, the persistent positive NAO induces anomalously strong westerlies over the North Atlantic subpolar region as a result of the intensified SLP gradient, enhancing the climatological westerlies (Fig. 10a). This pattern maximizes at 0 -yr lag by definition, and gradually diminishes as the low-frequency NAO pattern starts to switch sign at around 12-yr lag. This anomalous surface wind augments both the cold air advection from the continent as well as the relative wind speed, both acting to enhance the heat loss from the surface subpolar ocean (Fig. 10c). Previous studies have attributed the deepening of MLD and the subsequent AMOC increases to the anomalous heat fluxes associated with the NAO (e.g., Delworth and Zeng 2016). Here we also observe the apparent collocation of these two fields, such that MLD deepens over Labrador and Irminger Seas, where the turbulent heat fluxes are anomalously upward (Fig. 10d).

\section{b. Intensification and meridional excursion of the Gulf Stream and North Atlantic Current and their influence on the upper-ocean properties}

The NAO influence on the ocean also extends to the change in the ocean currents. With a development of NAO, the zero line of the wind stress curl shifts northward (Fig. 10b). Concomitantly, the Gulf Stream is intensified and shifted northward (Fig. 11), with this anomaly extending to the depth of approximately $1000 \mathrm{~m}$ (not shown). This result is consistent with the recent observational studies which illustrated that NAO leads the shift in the position of the Gulf Stream on a multidecadal time scale (McCarthy et al. 2015a, 2018; Nigam et al. 2018). In contrast, its extension, the North Atlantic Current, does not undergo the same shift. Initially (lag $-6 \mathrm{yr}$ ) the North Atlantic Current is also shifted northward relative to its climatological position; however, approximately from lag 0 year, while the Gulf Stream remains northward, the North Atlantic Current shifts its position southward. This southward shift is associated with the strengthening and expansion of the subpolar gyre, which is evident from the development of the anomalously low SSH over the subpolar gyre region (Fig. 12a).

The northward excursion of the Gulf Stream does not solely indicate the shift in the position but also indicates the increase in its volume transport, as shown in the observational study by Curry and McCartney (2001) based on hydrographic profiles. Thus, it is expected that we would also observe an increase in the upper ocean heat and salinity content as a result of the increased Gulf Stream transport, which advects warm and saline waters from the south. Indeed, we do see that both heat (Fig. 12b) and salt content (Fig. 12c) increase with the evolution of NAO, but with the salt content increase preceding that of heat by about 6 years, similar to the results obtained by Delworth et al. (1993). This difference in the timing of the heat and salt advection likely drives the oscillatory behavior of the AMOC, by initially augmenting the AMOC with the anomalously positive salinity advection, followed by the termination of the intensified phase of AMOC by the subsequent anomalously positive heat advection, as was suggested by Delworth et al. (1993). Our results from section 5 suggests that this increase in the upper-ocean heat content is chiefly a result of both the advective heat transport as 


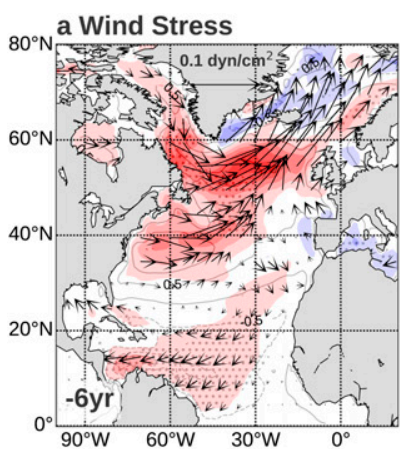

b Wind Stress Curl
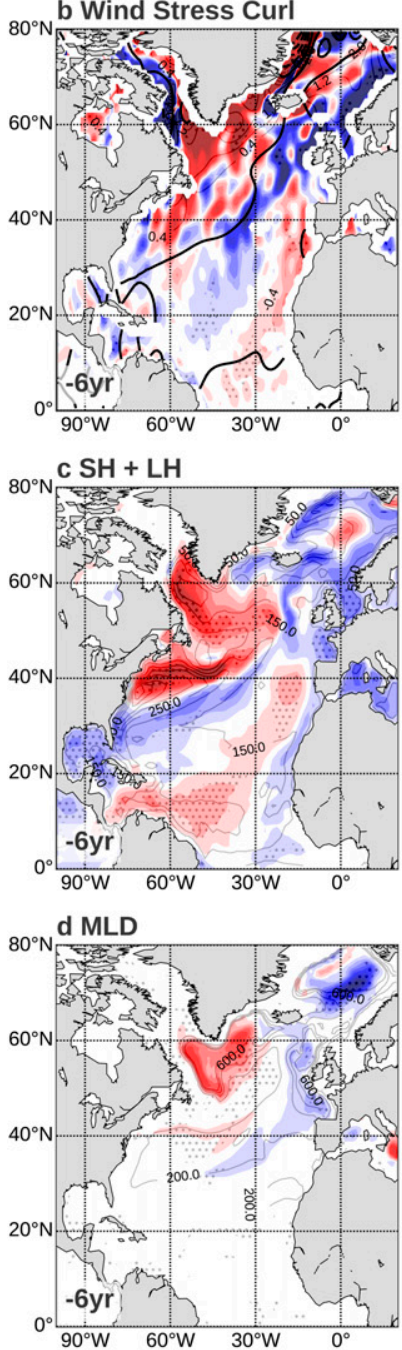
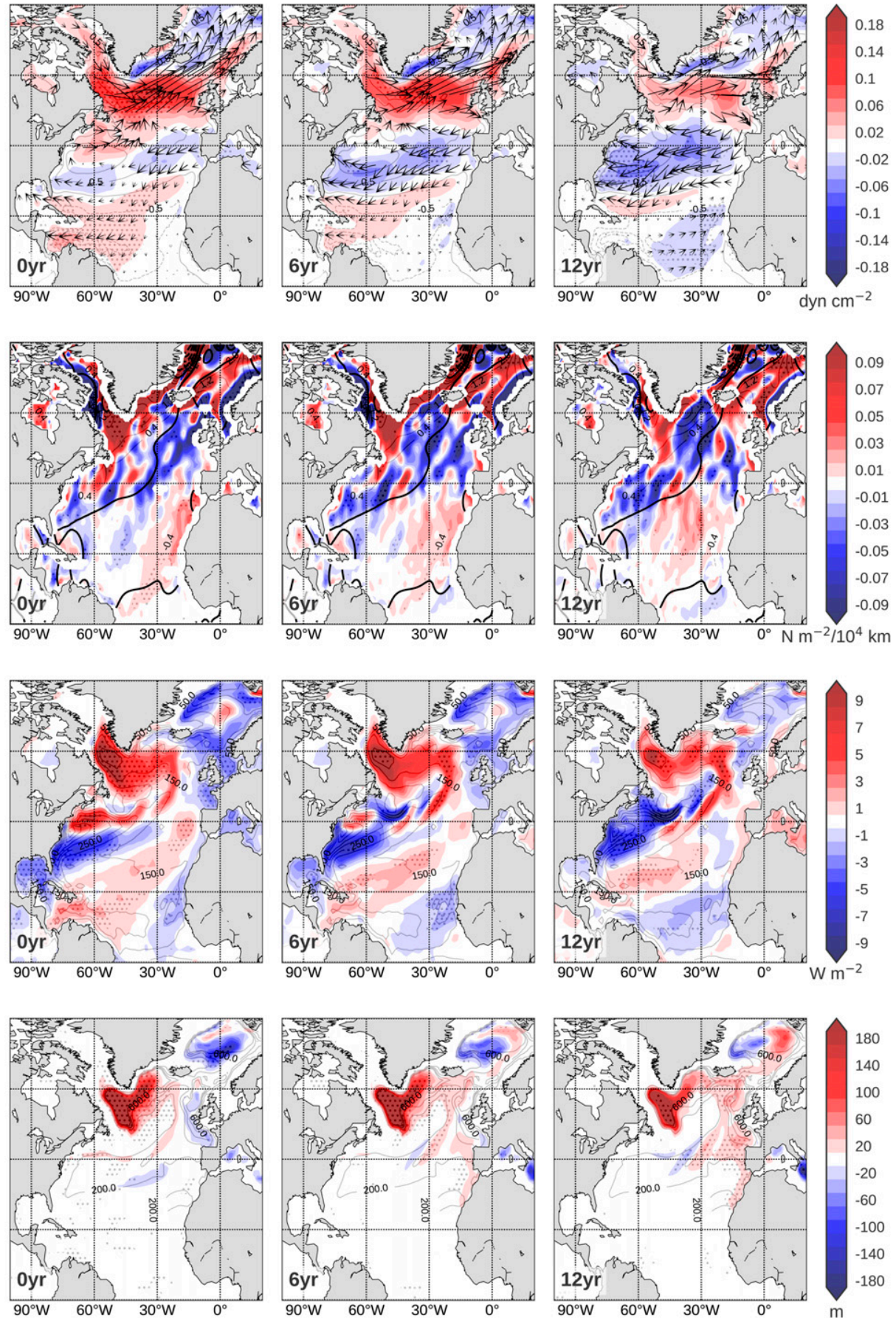

FIG. 10. Wintertime (JFM) (a) wind stress $\left(\right.$ dyn $\left.\mathrm{cm}^{-2}\right)$, (b) wind stress curl $\left(\mathrm{N} \mathrm{m}^{-2} 10^{4} \mathrm{~km}^{-1}\right)$, (c) turbulent heat fluxes (W m ${ }^{-2}$; sensible heat + latent heat fluxes), and (d) mixed layer depth (m), lag regressed on the multidecadal NAO index (40-70-yr frequency band; color shading), and overlaid on the wintertime climatological mean (gray contours). For the wind stress field, while the anomalies (color shading and arrows) show both $x$ and $y$ components of the field, the climatological mean is only the $x$ component in order to show the dominant zonal flow. The wintertime climatological zero line of the mean wind stress curl is shown in thick black contours (see second row). The sign convention of the turbulent heat fluxes is positive upward (in contrast to Fig. 8). Stippling indicates where the anomalies are statistically significant at the $95 \%$ level. 

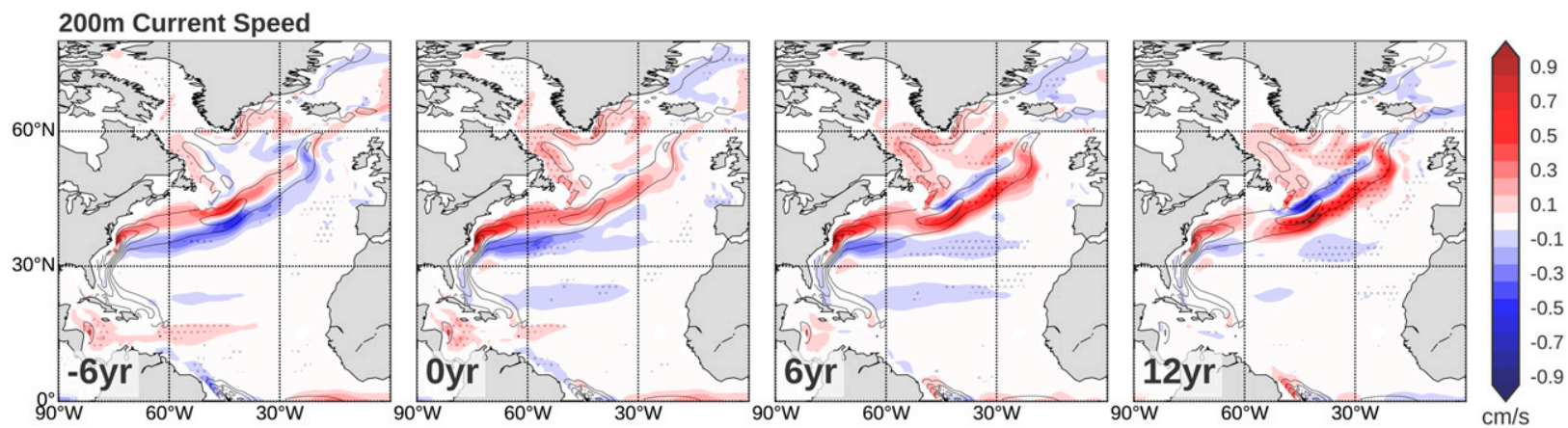

FIG. 11. Wintertime (JFM) 200-m-depth current speed $\left(\mathrm{cm} \mathrm{s}^{-1}\right)$ lag regressed on the multidecadal NAO index (shading), overlaid on the climatological 200-m-depth current speed, plotted for every $5 \mathrm{~cm} \mathrm{~s}^{-1}$ (black contours). Stippling indicates where the anomalies are statistically significant at the $95 \%$ level.

well as the MLD deepening, with the former mainly acting to warm the rim of the subpolar gyre. Decomposition of the heat and salt advection into the part that is due to the anomalous heat/salt and the part that is due to the anomalous current reveals that the increase in both anomalous heat and salt content is predominantly attributable to the anomalous current advecting the mean properties, with its main entry location into the subpolar gyre situated around $50^{\circ} \mathrm{N}, 20^{\circ} \mathrm{W}$ (not shown). The resultant anomalous potential density field (Fig. 12d) primarily reflects the anomalous salinity field over the subpolar region.

\section{c. Relative roles of turbulent heat fluxes and salinity advection in the MLD anomaly}

Finally, we investigate which of the two factors, the anomalous turbulent fluxes or the anomalous salinity, plays more significant role in deepening MLD over the subpolar gyre.

It is evident in Fig. 13 that the MLD deepening is well explained by the increase in the surface total density anomaly, suggesting the primary role of the surface ocean destabilization in triggering deep convection. The total density anomaly, in turn, is made up of the increase in the density anomaly due to the salinity increase, which is partially alleviated by the slightly lagged density anomaly due to the temperature increase. Turbulent heat fluxes also act to increase the density, but its effect is insignificant compared to that of the salinity. It is notable that the sensitivity of the MLD variability to the heat fluxes and salinity in MIROC6 is comparable to the observation on both interannual and longer time scales (not shown). Thus, although its value appears small (Fig. 12c), the corresponding salinity anomaly can induce an extensive MLD deepening. It is also apparent that the density anomaly due to the turbulent heat fluxes lags behind the total density anomaly, being almost concurrent with the density anomaly due to temperature. This synchronicity of the anomalous turbulent heat fluxes and the anomalous SST is in agreement with the observational study, which suggests that the low-frequency turbulent heat fluxes over the subpolar gyre is driven primarily by its underlying multidecadal SST signal (Gulev et al. 2013).

\section{Discussion and conclusions}

Using a state-of-the-art coupled general circulation model, MIROC6, we have investigated the mechanisms behind the multidecadal SST variability over the North Atlantic basin. Our findings based on the mixed-layer heat budget indicate that the AMO warming phase is mainly attributable to the MLD deepening. This deepened MLD increases the heat capacity, making the ocean less sensitive to the surface cooling by the heat fluxes, thereby leading to the relative warming. This anomalous MLD is primarily generated by the anomalous salinity increase over the subpolar region, induced by the intensified Gulf Stream following the positive NAO and the associated anomalous wind stress curl. Thus, our results shed new light on the important role of the MLD variability in creating the AMO-associated SST variability. This effect of the variable MLD has not been taken into consideration in the previous analyses, in which MLD is assumed to be invariant (e.g., Clement et al. 2015; Zhang et al. 2016; Cane et al. 2017; Garuba et al. 2018). Given the coordinated change in the MLD variability with the modulation of AMO, however, our results underscore the importance of including this effect in understanding the emergence of the AMO signal.

Our result supports the previous studies, which indicated that the ocean plays an important role in the emergence of the AMO spatial pattern, yet not precisely in the same context as the previous studies. While the previous studies have indicated the primary role of the change in the ocean heat content in creating the surface signature, our analysis suggests that the horizontal heat 

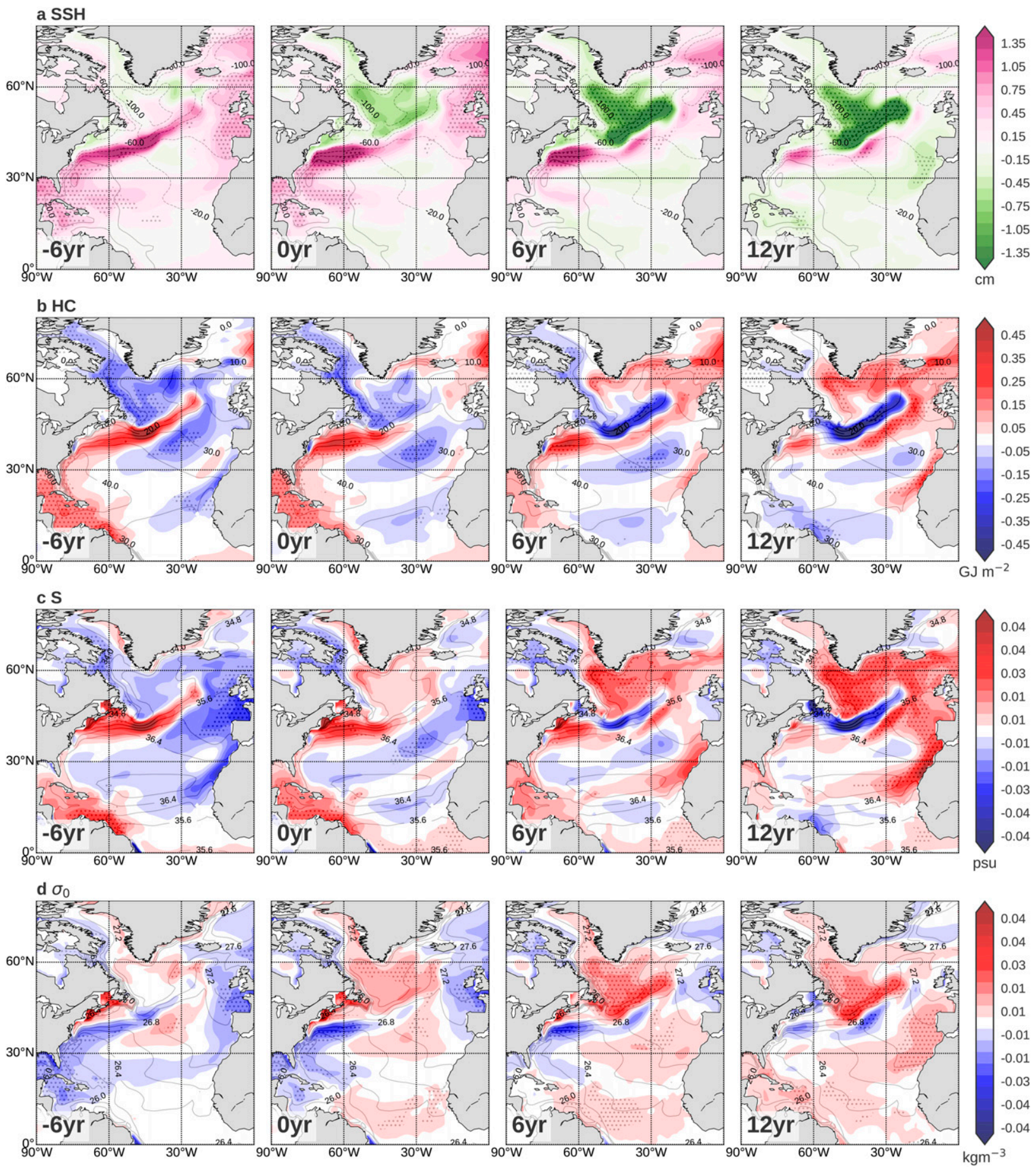

FIG. 12. As in Fig. 10, but for (a) sea surface height (cm), (b) top 500-m heat content ( $\left.\int \rho c_{p} T d z ; \mathrm{GJ} \mathrm{m}^{-2}\right)$, (c) top 500-m mean salinity (psu), and (d) top 500-m mean potential density $\left(\mathrm{kg} \mathrm{m}^{-3}\right)$. Stippling indicates where the anomalies are statistically significant at the $95 \%$ level.

advection does not act to warm the entire subpolar gyre, but warms only the rim of the gyre. Furthermore, when the vertical effect is also considered, the ocean overall acts to cool the region, in contrast to the previous notion. Rather, the increase in the heat content as well as the
SST signal associated with the positive AMO phase is a result of the competition between the cooling by the ocean terms and the warming by the heat flux term (Fig. 7) in the mixed layer temperature budget equation. The heat fluxes themselves, however, act to cool the 


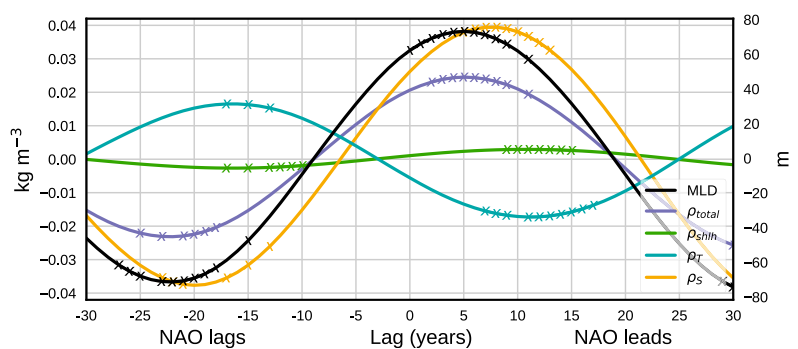

FIG. 13. Lag regression of surface total density $\rho_{\text {total }}$ (purple; $\mathrm{kg} \mathrm{m}^{-3}$ ), surface density anomaly due to the turbulent fluxes $\rho_{\text {shlh }}$ (green), due to the temperature anomaly $\rho_{T}$ (cyan), and due to the salinity anomaly $\rho_{S}$ (yellow), on the multidecadal NAO index. All the density anomalies are quantified over the subpolar gyre region, defined over the region encircled by the black square in Fig. 7. The mixed layer depth anomaly over the subpolar region $(\mathrm{m})$ is also plotted in black. The crosses indicate where the anomalies are statistically significant at the $95 \%$ level.

subpolar North Atlantic in the model, in agreement with the observation (Gulev et al. 2013) and the other coupled climate models (Zhang et al. 2016; O'Reilly et al. 2016), and thus heat fluxes alone do not act to warm. Instead, the significance of the heat fluxes arises only when considered together with the MLD variability, which in turn is a result of both heat fluxes and the ocean dynamics, with the latter playing a predominant role. In this regard, our result could be interpreted to support both sides of the previous arguments on the development of the AMO signal, depending on how we regard the role of the MLD variability, yet by slightly modifying the previous notions in either case. That is, when we consider the MLD variation as a part of the heat flux term in the mixed-layer temperature budget, our result is in line with the claims by Clement et al. (2015), underscoring the importance of the heat fluxes. In contrast, our result buttresses the role of the ocean as suggested by the other studies (e.g., Delworth et al. 1993; Latif et al. 2004; Knight et al. 2005; Kim et al. 2018), when highlighting the fact that this MLD variability is primarily created by the ocean dynamics. As our analysis is based on a single climate model, the relative importance of the mechanisms we found in the current study in comparison to the conventional mechanisms remains to be investigated in other climate models in future studies.

The intensification and the northward shift in the Gulf Stream associated with the overlying NAO state are in agreement with the previous observational (McCarthy et al. 2015a, 2018; Nigam et al. 2018) and theoretical studies (Cessi et al. 2004). Our analysis suggests that its extension, the North Atlantic Current, is also intensified; however, it does not follow the same northward shift but it shifts southward owing to the concurrent expansion and intensification of the subpolar gyre. Interestingly, this result is at odds with a study by Zhang (2008), who, based on the observed SSH and subsurface temperature as well as results from a coupled climate model, showed precisely the opposite, finding a southward shift of Gulf Stream and weaker subpolar gyre associated with the strengthening of AMOC. Thus, our results exhibit the similar "AMOC fingerprint" consisting of the subpolar gyre warming and the Gulf Stream cooling, but for different reasons. This intriguing discrepancy demands further analysis in the future. It is of particular importance given its implication on the projected weakening of the AMOC under the global warming (Kirtman et al. 2013), as the implied AMOC state from the SST signature would imply the complete opposite tendency.

Our results also indicate that in MIROC6 there possibly exists a multidecadal feedback loop among NAO, AMOC, and AMO, while in a stark contrast this multidecadal link is absent from its precedent version, MIROC5 (not shown). Although further investigation is required, this improvement in representation of the multidecadal relationship in MIROC6 over MIROC5 may be attributable to the enhanced signal of the multidecadal NAO, not only compared with MIROC5 but also with majority of the other CMIP5 models. Previous studies have highlighted the importance of the correct representation of the AMO tropical arm via the radiative feedbacks (Brown et al. 2016; Yuan et al. 2016) from which the atmospheric Rossby waves may emanate (Davini et al. 2015; Peings and Magnusdottir 2016; Peings et al. 2016), as well as of the stratosphere, leading to the better stratosphere-troposphere dynamical coupling (Omrani et al. 2014, 2015; Peings et al. 2016) in simulating the link between AMO and the oppositesigned NAO. As has been described in section 2a, MIROC6 is a high-top model with a better shallow convection scheme unlike the majority of the CMIP5 models, and thus both of these suggested effects may be in play. Figure 9, however, indicates that the tropical arm in MIROC6 is likely a result not of the shortwave radiation but of the latent heat flux. The current observational record is still too short to ascertain this relationship; however, if this feedback truly exists in the climate system, understanding the mechanism behind this multidecadal relationship has an important implication for the predictability. With the nature of the AMOC and North Atlantic subpolar SST likely undergoing changes under the global warming (Kirtman et al. 2013; Rahmstorf et al. 2015), it is especially important to understand whether the current relationship will remain unaltered or be subject to some changes. These oceanic changes will in turn likely affect the response to the overlying atmosphere. Thus, in the subsequent study, we will further investigate this multidecadal feedback loop, 
particularly focusing on the mechanisms behind the multidecadal NAO in the model.

Acknowledgments. We thank Drs. A. Czaja, Y. Tanimoto, S. Minobe, and Y. Morioka, colleagues at APL, and three anonymous reviewers for their insightful comments and suggestions that significantly improved the earlier versions of this manuscript. This project was supported by the Japan Society for the Promotion of Science (JSPS) KAKENHI Grants JP18K13615, JP19H05701, JP18H03726, 15H05825, and $19 \mathrm{H} 01962$ and the Integrated Research Program for Advancing Climate Models (TOUGOU Program) from the Ministry of Education, Culture, Sports, Science, and Technology (MEXT).

Data availability statement. The MIROC6 data that support the findings of this study are available from WCRP Coupled Model Intercomparison Project website (https://esgf-node.llnl.gov/projects/cmip6/).

\section{REFERENCES}

Allan, R., and T. Ansell, 2006: A new globally complete monthly historical gridded mean sea level pressure dataset (HadSLP2): 1850-2004. J. Climate, 19, 5816-5842, https://doi.org/10.1175/ JCLI3937.1.

Bjerknes, J., 1964: Atlantic air-sea interaction. Advances in Geophysics, H. E. Landsberg, and J. Van Mieghem, Eds., Academic Press, 1-82.

Booth, B. B. B., N. J. Dunstone, P. R. Halloran, T. Andrews, and N. Bellouin, 2012: Aerosols implicated as a prime driver of twentieth-century North Atlantic climate variability. Nature, 484, 228-232, https://doi.org/10.1038/nature10946.

Brown, P. T., M. S. Lozier, R. Zhang, and W. Li, 2016: The necessity of cloud feedback for a basin-scale Atlantic Multidecadal Oscillation. Geophys. Res. Lett., 43, 3955-3963, https://doi.org/ 10.1002/2016GL068303.

Caesar, L., S. Rahmstorf, A. Robinson, G. Feulner, and V. Saba, 2018: Observed fingerprint of a weakening Atlantic Ocean overturning circulation. Nature, 556, 191-196, https://doi.org/ 10.1038/s41586-018-0006-5.

Cane, M. A., A. C. Clement, L. N. Murphy, and K. Bellomo, 2017: Low-pass filtering, heat flux, and Atlantic multidecadal variability. J. Climate, 30, 7529-7553, https://doi.org/10.1175/ JCLI-D-16-0810.1.

Cessi, P., K. Bryan, and R. Zhang, 2004: Global seiching of thermocline waters between the Atlantic and the Indian-Pacific Ocean basins. Geophys. Res. Lett., 31, L04302, https://doi.org/ 10.1029/2003GL019091.

Clement, A., K. Bellomo, L. N. Murphy, M. A. Cane, T. Mauritsen, G. Rädel, and B. Stevens, 2015: The Atlantic Multidecadal Oscillation without a role for ocean circulation. Science, $\mathbf{3 5 0}$, 320-324, https://doi.org/10.1126/science.aab3980.

_ M. A. Cane, L. N. Murphy, K. Bellomo, T. Mauritsen, and B. Stevens, 2016: Response to comment on "The Atlantic Multidecadal Oscillation without a role for ocean circulation." Science, 352, 1527, https://doi.org/10.1126/science.aaf2575.

Curry, R. G., and M. S. McCartney, 2001: Ocean gyre circulation changes associated with the North Atlantic Oscillation. J. Phys.
Oceanogr., 31, 3374-3400, https://doi.org/10.1175/1520-0485(2001) 031<3374:OGCCAW>2.0.CO;2.

Danabasoglu, G., 2008: On multidecadal variability of the Atlantic meridional overturning circulation in the Community Climate System Model version 3. J. Climate, 21, 5524-5544, https:// doi.org/10.1175/2008JCLI2019.1.

Davini, P., J. von Hardenberg, and S. Corti, 2015: Tropical origin for the impacts of the Atlantic multidecadal variability on the Euro-Atlantic climate. Environ. Res. Lett., 10, 094010, https:// doi.org/10.1088/1748-9326/10/9/094010.

Delworth, T. L., and R. J. Greatbatch, 2000: Multidecadal thermohaline circulation variability driven by atmospheric surface flux forcing. J. Climate, 13, 1481-1495, https://doi.org/ 10.1175/1520-0442(2000)013<1481:MTCVDB > 2.0.CO;2.

, and F. Zeng, 2016: The impact of the North Atlantic Oscillation on climate through its influence on the Atlantic meridional overturning circulation. J. Climate, 29, 941-962, https://doi.org/10.1175/JCLI-D-15-0396.1.

_ S. Manabe, and R. Stouffer, 1993: Interdecadal variations of the thermohaline circulation in a coupled ocean-atmosphere model. J. Climate, 6, 1993-2011, https://doi.org/10.1175/15200442(1993)006,1993:IVOTTC.2.0.CO;2.

Deser, C., M. A. Alexander, S.-P. Xie, and A. S. Phillips, 2010: Sea surface temperature variability: Patterns and mechanisms. Annu. Rev. Mar. Sci., 2, 115-143, https://doi.org/10.1146/ annurev-marine-120408-151453.

Eden, C., and J. Willebrand, 2001: Mechanism of interannual to decadal variability of the North Atlantic circulation. J. Climate, 14, 2266-2280, https://doi.org/10.1175/1520-0442(2001)014<2266: MOITDV $>2.0 . \mathrm{CO} ; 2$

Feldstein, S. B., and C. L. Franzke, 2017: Atmospheric teleconnection patterns. Nonlinear and Stochastic Climate Dynamics, Cambridge University Press, 54-104.

Garuba, O. A., J. Lu, H. A. Singh, F. Liu, and P. Rasch, 2018: On the relative roles of the atmosphere and ocean in the Atlantic Multidecadal Variability. Geophys. Res. Lett., 45, 9186-9196, https://doi.org/10.1029/2018GL078882.

Goldenberg, S. B., C. W. Landsea, M. Mestas-Nunez, and W. M. Gray, 2001: The recent increase in Atlantic hurricane activity: Causes and implications. Science, 293, 474-479, https://doi.org/ 10.1126/science. 1060040 .

Griffies, S. M., and Coauthors, 2015: Impacts on ocean heat from transient mesoscale eddies in a hierarchy of climate models. J. Climate, 28, 952-977, https://doi.org/10.1175/JCLI-D-14-00353.1.

Guinehut, S., A. L. Dhomps, G. Larnicol, and P.-Y. Le Traon, 2012: High resolution 3-D temperature and salinity fields derived from in situ and satellite observations. Ocean Sci., 8, 845-857, https://doi.org/10.5194/os-8-845-2012.

Gulev, S. K., M. Latif, N. Keenlyside, W. Park, and K. P. Koltermann, 2013: North Atlantic Ocean control on surface heat flux on multidecadal timescales. Nature, 499, 464-467, https://doi.org/10.1038/nature12268.

Hasumi, H., 2000: CCSR Ocean Component Model (COCO) version 2.1. Tech. Rep. 13, Center for Climate System Research, University of Tokyo, $68 \mathrm{pp}$.

Hirahara, S., M. Ishii, and Y. Fukuda, 2014: Centennial-scale sea surface temperature analysis and its uncertainty. J. Climate, 27, 57-75, https://doi.org/10.1175/JCLI-D-12-00837.1.

Hurrell, J. W., 1995: Decadal trends in the North Atlantic Oscillation: Regional temperatures and precipitation. Science, 269, 676-679, https://doi.org/10.1126/science.269.5224.676. , Y. Kushnir, G. Ottersen, and M. Visbeck, 2013: An overview of the North Atlantic Oscillation. The North Atlantic Oscillation. 
Geophys. Monogr., Vol. 134, Amer. Geophys. Union, 1-35, https://doi.org/10.1029/GM134.

Kim, W. M., S. Yeager, P. Chang, and G. Danabasoglu, 2018: Lowfrequency North Atlantic climate variability in the Community Earth System Model large ensemble. J. Climate, 31, 787-813, https://doi.org/10.1175/JCLI-D-17-0193.1.

Kirtman, B., and Coauthors, 2013: Near-term climate change: Projections and predictability. Climate Change 2013: The Physical Science Basis, T. F. Stocker et al., Eds., Cambridge University Press, 953-1028.

Knight, J. R., R. J. Allan, C. K. Folland, M. Vellinga, and M. E. Mann, 2005: A signature of persistent natural thermohaline circulation cycles in observed climate. Geophys. Res. Lett., 32, L20708, https://doi.org/10.1029/2005GL024233.

Knudsen, M. F., M.-S. Seidenkrantz, B. H. Jacobsen, and A. Kuijpers, 2011: Tracking the Atlantic Multidecadal Oscillation through the last 8,000 years. Nat. Commun., 2, 178, https://doi.org/10.1038/ ncomms1186.

Kushnir, Y., 1994: Interdecadal variations in North Atlantic sea surface temperature and associated atmospheric conditions. J. Climate, 7, 141-157, https://doi.org/10.1175/1520-0442(1994) 007<0141:IVINAS $>2.0$.CO;2.

Kwon, Y.-O., and C. Frankignoul, 2014: Mechanisms of multidecadal Atlantic Meridional overturning circulation variability diagnosed in depth versus density space. J. Climate, 27, 9359-9376, https://doi.org/10.1175/JCLI-D-14-00228.1.

Latif, M., and Coauthors, 2004: Reconstructing, monitoring, and predicting multidecadal-scale changes in the North Atlantic thermohaline circulation with sea surface temperature. J. Climate, 17, 1605-1614, https://doi.org/10.1175/1520-0442(2004)017<1605: RMAPMC $>2.0 . \mathrm{CO} ; 2$.

Lu, R. Y., B. W. Dong, and H. Ding, 2006: Impact of the Atlantic Multidecadal Oscillation on the Asian summer monsoon. Geophys. Res. Lett., 33, L24701, https://doi.org/ 10.1029/2006GL027655.

Marshall, J., H. Johnson, and J. Goodman, 2001: A study of the interaction of the North Atlantic Oscillation with ocean circulation. J. Climate, 14, 1399-1421, https://doi.org/10.1175/ 1520-0442(2001)014<1399:ASOTIO>2.0.CO;2.

McCarthy, G. D., I. D. Haigh, J. J.-M. Hirschi, J. P. Grist, and D. A. Smeed, 2015a: Ocean impact on decadal Atlantic climate variability revealed by sea-level observations. Nature, 521, 508-510, https://doi.org/10.1038/nature14491.

— Overturning circulation at $26^{\circ}$ N. Prog. Oceanogr., 130, $91-111$, https://doi.org/10.1016/j.pocean.2014.10.006.

— T. M. Joyce, and S. A. Josey, 2018: Gulf Stream variability in the context of quasi-decadal and multi-decadal Atlantic climate variability. Geophys. Res. Lett., 45, 11 257-11 264, https:// doi.org/10.1029/2018GL079336.

Morioka, Y., T. Tozuka, and T. Yamagata, 2010: Climate variability in the southern Indian Ocean as revealed by selforganizing maps. Climate Dyn., 35, 1059-1072, https://doi.org/ 10.1007/s00382-010-0843-x.

,-- , S. Masson, P. Terray, J. J. Luo, and T. Yamagata, 2012: Subtropical dipole modes simulated in a coupled general circulation model. J. Climate, 25, 4029-4047, https://doi.org/ 10.1175/JCLI-D-11-00396.1.

Msadek, R., and C. Frankignoul, 2009: Atlantic multidecadal oceanic variability and its influence on the atmosphere in a climate model. Climate Dyn., 33, 45-62, https://doi.org/10.1007/s00382-008-0452-0.

Nigam, S., A. Ruiz-Barradas, and L. Chafik, 2018: Gulf Stream excursions and sectional detachments generate the decadal pulses in the Atlantic multidecadal oscillation. J. Climate, 31, 2853-2870, https://doi.org/10.1175/JCLI-D-17-0010.1.

Numaguti, A., S. Sugata, M. Takahashi, T. Nakajima, and A. Sumi, 1997: Description of CCSR-NIES atmospheric general circulation model. Tech. Rep., Center for Global Environmental Reserch, National Institute for Environmental Studies, 48 pp.

Omrani, N.-E., N. S. Keenlyside, J. Bader, and E. Manzini, 2014: Stratosphere key for wintertime atmospheric response to warm Atlantic decadal conditions. Climate Dyn., 42, 649-663, https://doi.org/10.1007/s00382-013-1860-3.

_, J. Bader, N. S. Keenlyside, and E. Manzini, 2015: Tropospherestratosphere response to large-scale North Atlantic Ocean variability in an atmosphere/ocean coupled model. Climate Dyn., 46, 1397-1415, https://doi.org/10.1007/s00382-015-2654-6.

O'Reilly, C. H., and L. Zanna, 2018: The signature of oceanic processes in decadal extratropical SST anomalies. Geophys. Res. Lett., 45, 7719-7730, https://doi.org/10.1029/2018GL079077.

_- M. Huber, T. Woollings, and L. Zanna, 2016: The signature of low-frequency oceanic forcing in the Atlantic Multidecadal Oscillation. Geophys. Res. Lett., 43, 2810-2818, https://doi.org/ 10.1002/2016GL067925.

_ - T. Woollings, and L. Zanna, 2017: The dynamical influence of the Atlantic multidecadal oscillation on continental climate. J. Climate, 30, 7213-7230, https://doi.org/10.1175/JCLI-D-160345.1.

Otterå, O. H., M. Bentsen, H. Drange, and L. Suo, 2010: External forcing as a metronome for Atlantic multidecadal variability. Nat. Geosci., 3, 688-694, https://doi.org/10.1038/ngeo955.

Park, S., and C. S. Bretherton, 2009: The University of Washington shallow convection and moist turbulence schemes and their impact on climate simulations with the Community Atmosphere Model. J. Climate, 22, 3449-3469, https://doi.org/10.1175/2008JCLI2557.1.

Peings, Y., and G. Magnusdottir, 2014: Forcing of the wintertime atmospheric circulation by the multidecadal fluctuations of the North Atlantic Ocean. Environ. Res. Lett., 9, 034018, https:// doi.org/10.1088/1748-9326/9/3/034018.

$\longrightarrow$, and - 2016: Wintertime atmospheric response to Atlantic multidecadal variability: Effect of stratospheric representation and ocean-atmosphere coupling. Climate Dyn., 47, 10291047, https://doi.org/10.1007/s00382-015-2887-4.

_, G. Simpkins, and G. Magnusdottir, 2016: Multidecadal fluctuations of the North Atlantic Ocean and feedback on the winter climate in CMIP5 control simulations. J. Geophys. Res. Atmos., 121, 2571-2592, https://doi.org/10.1002/2015JD024107.

Qiu, B., and K. A. Kelly, 1993: Upper-ocean heat balance in the Kuroshio Extension region. J. Phys. Oceanogr., 23, 2027 2041, https://doi.org/10.1175/1520-0485(1993)023<2027: $\mathrm{UOHBIT}>2.0 . \mathrm{CO} ; 2$.

Rahmstorf, S., J. E. Box, G. Feulner, M. E. Mann, A. Robinson, S. Rutherford, and E. J. Schaffernicht, 2015: Exceptional twentieth-century slowdown in Atlantic Ocean overturning circulation. Nat. Climate Change, 5, 475-480, https://doi.org/ 10.1038/NCLIMATE2554.

Rowell, B. D. P., C. K. Folland, K. Maskell, and M. N. Ward, 1995: Variability of summer rainfall over tropical North Africa (1906-92): Observations and modelling. Quart. J. Roy. Meteor. Soc., 121, 669-704, https://doi.org/10.1002/qj.49712152311.

Ruprich-Robert, Y., R. Msadek, F. Castruccio, S. Yeager, T. Delworth, and G. Danabasoglu, 2017: Assessing the climate impacts of the observed Atlantic multidecadal variability using the GFDL CM2.1 and NCAR CESM1 global coupled models. J. Climate, 30, 2785-2810, https://doi.org/ 10.1175/JCLI-D-16-0127.1. 
Schlesinger, M. E., and N. Ramankutty, 1994: An oscillation in the global climate system of period $65-70$ years. Science, $\mathbf{3 6 7}, 723$ 726, https://doi.org/10.1038/367723A0.

Sutton, R. T., and B. Dong, 2012: Atlantic Ocean influence on a shift in European climate in the 1990s. Nat. Geosci., 5, 788792, https://doi.org/10.1038/ngeo1595.

Tatebe, H., and M. Watanabe, 2018: MIROC MIROC6 model output prepared for CMIP6 CMIP piControl. Earth System Grid Federation, accessed 12 December 2018, https://doi.org/ 10.22033/ESGF/CMIP6.5711.

, and Coauthors, 2019: Description and basic evaluation of simulated mean state, internal variability, and climate sensitivity in MIROC6. Geosci. Model Dev., 12, 2727-2765, https:// doi.org/10.5194/gmd-12-2727-2019.

Terray, L., 2012: Evidence for multiple drivers of North Atlantic multi-decadal climate variability. Geophys. Res. Lett., 39, L19712, https://doi.org/10.1029/2012GL053046.

Ting, M., Y. Kushnir, R. Seager, and C. Li, 2009: Forced and internal twentieth-century SST trends in the North Atlantic. J. Climate, 22, 1469-1481, https://doi.org/10.1175/2008JCLI2561.1.

Torrence, C., and G. P. Compo, 1998: A practical guide to wavelet analysis. Bull. Amer. Meteor. Soc., 79, 61-78, https://doi.org/ 10.1175/1520-0477(1998)079<0061:APGTWA > 2.0.CO;2.

Visbeck, M., E. P. Chassignet, R. Curry, T. L. Delworth, B. Dickson, and G. Krahmann, 2003: The ocean's response to North Atlantic Oscillation variability. The North Atlantic Oscillation: Climatic Significance and Environmental Impact, Geophys. Monogr., Vol. 134, Amer. Geophys. Union, 113 145, https://doi.org/10.1029/134GM06.

Wang, X., J. Li, C. Sun, and T. Liu, 2017: NAO and its relationship with the Northern Hemisphere mean surface temperature in CMIP5 simulations. J. Geophys. Res. Atmos., 122, 4202-4227, https://doi.org/10.1002/2016JD025979.
Woollings, T., C. Franzke, D. L. R. Hodson, B. Dong, E. A. Barnes, C. C. Raible, and J. G. Pinto, 2014: Contrasting interannual and multidecadal NAO variability. Climate Dyn., 45, 539-556, https://doi.org/10.1007/S00382-014-2237-Y.

Yamamoto, A., and J. B. Palter, 2016: The absence of an Atlantic imprint on the multidecadal variability of wintertime European temperature. Nat. Commun., 7, 10930, https://doi.org/10.1038/ ncomms10930.

- _ - M. S. Lozier, M. S. Bourqui, and S. J. Leadbetter, 2015: Ocean versus atmosphere control on western European wintertime temperature variability. Climate Dyn., 45, 3593-3607, https://doi.org/10.1007/S00382-015-2558-5.

Yan, X., R. Zhang, and T. R. Knutson, 2018: Underestimated AMOC variability and implications for AMV and predictability in CMIP models. Geophys. Res. Lett., 45, 4319-4328, https://doi.org/10.1029/2018GL077378.

Yasuda, I., T. Tozuka, M. Noto, and S. Kouketsu, 2000: Heat balance and regime shifts of the mixed layer in the Kuroshio Extension. Prog. Oceanogr., 47, 257-278, https://doi.org/10.1016/ S0079-6611(00)00038-0.

Yuan, T., L. Oreopoulos, M. Zelinka, H. Yu, J. R. Norris, M. Chin, S. Platnick, and K. Meyer, 2016: Positive low cloud and dust feedbacks amplify tropical North Atlantic Multidecadal Oscillation. Geophys. Res. Lett., 43, 1349-1356, https:// doi.org/10.1002/2016GL067679.

Zhang, R., 2008: Coherent surface-subsurface fingerprint of the Atlantic meridional overturning circulation. Geophys. Res. Lett., 35, L20705, https://doi.org/10.1029/2008GL035463.

_, R. Sutton, G. Danabasoglu, T. L. Delworth, W. M. Kim, J. Robson, and S. G. Yeager, 2016: Comment on "The Atlantic Multidecadal Oscillation without a role for ocean circulation." Science, 352, 1527, https://doi.org/10.1126/ science.aaf1660. 